NBER WORKING PAPER SERIES

\title{
LABOR MARKET POLARIZATION AND THE GREAT DIVERGENCE: THEORY AND EVIDENCE
}

\author{
Donald R. Davis \\ Eric Mengus \\ Tomasz K. Michalski \\ Working Paper 26955 \\ http://www.nber.org/papers/w26955 \\ NATIONAL BUREAU OF ECONOMIC RESEARCH \\ 1050 Massachusetts Avenue \\ Cambridge, MA 02138 \\ April 2020
}

We would like to thank David Autor, Iain Bamford, Dominick Barthelme, Mehdi Benatiya Andaloussi, Wolfgang Dauth, Jorge De La Roca, Laurent Gobillon, James Harrigan, Reka Juhasz, Maxime Liegey, Bentley MacLeod, Alan Manning, David Nagy, and Giacomo A. M. Ponzetto as well as seminar participants at EIEF, IGC, Kraks Fond, OECD, PSU, Queens College, SMU, UAB, UEA annual meeting 2018 (New York), Université Paris-Saclay, Joint French Macro workshop 2018, 7th workshop on "Structural Change and Macroeconomic Dynamics" (Cagliari), NBER ITI Spring 2019, 2019 European meetings of the UEA (Amsterdam), 2019 NBER Summer Institute ("Income Distribution and Macroeconomics" and "Urban Economics"), HEC Paris Workshop on Firm Location and Economic Geography, 2019 CURE conference for helpful comments and discussions. This work was supported by Investissements d'Avenir [grant number ANR-11-IDEX-0003/Labex Ecodec/ANR-11LABX-0047]. The views expressed herein are those of the authors and do not necessarily reflect the views of the National Bureau of Economic Research.

NBER working papers are circulated for discussion and comment purposes. They have not been peer-reviewed or been subject to the review by the NBER Board of Directors that accompanies official NBER publications.

(C) 2020 by Donald R. Davis, Eric Mengus, and Tomasz K. Michalski. All rights reserved. Short sections of text, not to exceed two paragraphs, may be quoted without explicit permission provided that full credit, including ( $)$ notice, is given to the source. 
Labor Market Polarization and the Great Divergence: Theory and Evidence

Donald R. Davis, Eric Mengus, and Tomasz K. Michalski

NBER Working Paper No. 26955

April 2020

JEL No. J21,R12,R13

\begin{abstract}
In recent decades, middle-paid jobs have declined, replaced by a mix of high and low-paid jobs. This is labor market polarization. At the same time, initially skilled and typically larger cities have become even more skilled relative to initially less skilled and typically smaller cities. This is the great divergence. We develop a theory that links these two phenomena. We draw on existing models of polarization and heterogeneous labor in spatial equilibrium, adding to these a sharper interaction of individual-and city-level comparative advantage. We then confront the predictions of the theory with detailed data on occupational growth for a sample of 117 French cities. We find, consistent with our theory, that middle-paid jobs decline most sharply in larger cities; that these lost jobs are replaced two-to-one by high-paid jobs in the largest cities and two-to-one by low-paid jobs in the smallest cities; and that the lost middle-paid jobs are concentrated in an upper tier in the large cities and a lower tier in the smaller cities.
\end{abstract}

Donald R. Davis

Department of Economics

Columbia University

1004 International Affairs Building

420 West 118th St.

New York, NY 10027

and NBER

drd28@columbia.edu

Eric Mengus

HEC Paris

Economics and Decisions Sciences Department

1 rue de la Libération

78350 Jouy en Josas

France

mengus@hec.fr
Tomasz K. Michalski

HEC Paris

Economics and Decisions Sciences Department

1 rue de la Libération

78350 Jouy en Josas

France

michalski@hec.fr

An online appendix is available at http://www.nber.org/data-appendix/w26955 


\section{Introduction}

Two of the most important features of advanced labor markets in the past quarter century are labor market polarization and the great divergence. Labor market polarization concerns the growth of jobs in high- and low-paid categories and the decline of middle-paid jobs. The great divergence is an explicitly spatial theory about the growth of high skill jobs in initially skilled, typically larger cities relative to initially less skilled, typically smaller cities.

There is by now a vast literature on labor market polarization and an important, if smaller, literature related to the great divergence. Yet these literatures have essentially no contact in spite of describing the same labor markets over the same time period, each with some prominent spatial dimension. The literature on the great divergence by and large proceeds in frameworks that cannot accommodate labor market polarization. The literature on labor market polarization has an explicit if simplified spatial structure capable of addressing the question of the great divergence, but has not made this aspect of local labor markets a focus. And the most prominent spatial prediction of the labor market polarization literature, which links the decline of one class of middle-paid jobs to the initial exposure to those jobs, is not robust to considering the broader decline of middle-paid jobs, arguably the larger project at hand.

This paper addresses, in theory and data, how to understand labor market polarization and the great divergence in a common framework. This unification highlights features of the experience that would not be obvious considering either in isolation. We build on key features of the Autor and Dorn (2013) model that are well-suited to consider shocks from offshoring and routinization. We insert these into a modified Davis and Dingel (2020) continuum-of-skills, spatial equilibrium model. Together these yield key predictions regarding the evolution of labor markets across cities of different sizes in response to an offshoring or routinization shock. Importantly these predictions include both labor market polarization in all cities as well as a great divergence across cities.

We examine these theoretical predictions for a set of 117 French cities over the period 19942015. In simple form, our results identify two Frances. Labor market polarization is ubiquitous but divergent. In the France of large cities, the loss of middle paid jobs is sharper, but these middle-paid jobs are primarily replaced by high-paid jobs. In the France of small cities, the loss of middle-paid jobs is strong if more moderate, and the middle-paid jobs are primarily replaced by low-paid jobs.

In sum, there are a number of novel contributions. This is the first paper to provide a common theoretical framework for understanding both labor market polarization and the great divergence. As such, it is also the first to explain the great divergence without relying specifically on some form of skill-biased technical change as the driving force. Our theory predicts that labor market polarization will occur both in the aggregate and in all cities, but that it will manifest differently in large and small cities. Under the specified conditions, our theory predicts that large cities will experience a sharper decline in middle-paid jobs, that these job losses will be concentrated in an upper tier of the middle-paid jobs, and that they will be primarily replaced by high-paid jobs. By 
contrast, in smaller cities, there will be a more modest decline of middle-paid jobs, these job losses will be relatively concentrated in the lower tier of middle-paid jobs, and the lost middle-paid jobs will be replaced to a greater extent by low-paid jobs. Our empirical work provides strong support for many predictions of our theory. These include not only the motivating aggregate targets such as labor market polarization and the great divergence, but also more novel predictions about the contrasting experience across cities of different size. The results also provide caution about the use of measures of local exposure to middle-paid jobs as also indicating vulnerability to loss of these jobs, which is true for a class of middle-paid jobs but not for middle-paid jobs as a whole.

\subsection{Polarization, Divergence, and Skills: An Analytic Framework}

Our model examines the consequences of offshoring and routinization shocks in a system of cities model in full spatial equilibrium across sectors and locations. As such, the model focuses on long run adjustment to shocks rather than transitional dynamics. Workers of heterogeneous productivity choose a sector of production, a city, and a location within the city. The model features a continuum of worker types and three intermediate productive sectors of employment. Productivity differences exist across both workers and cities. Higher skill workers have an absolute productivity advantage within any sector and the strength of this advantage is greater in higher-paid sectors. We provide a simple specification of these advantages that makes productivity increasing in skill in all sectors, but in a concave way in low-paid sectors; linear in middle-paid sectors; and sufficiently convex in highpaid sectors. This is of particular consequence when we consider the translation of common shocks to jobs gained and lost in different sectors across cities of different sizes. In addition to absolute advantages of higher skill workers within each sector, these advantages are log-supermodular, so that the relative productivity advantage of high skill workers is stronger in higher-paid sectors.

Our baseline model focuses on a case with two cities with heterogeneous productivity. One city has higher productivity in each sector of employment and comparative advantage in highrelative to middle-, and middle- relative to low-paid sectors. The cities will in equilibrium have overlapping skill distributions as an interval of workers will be willing to trade off the advantages of residence in a more productive city against occupying a less productive location within that city. The equilibrium features a log-supermodular distribution of skills across cities, so that the more productive and in equilibrium larger city has relatively more of higher skilled workers. Within each city, comparative advantage across workers insures an ordering across workers so that the lowest skill workers are in the low-paid sector, a middle interval of skills in the middle-paid sector, and only the highest skill workers in the high-paid sector. Productivity advantages across cities insures that there is a strict ordering of the cutoffs in sectoral allocations of skills. The boundary worker between high and middle-paid sectors will be of lower skill in the larger, more productive city as these advantages compensate for the lower worker-level comparative advantage in the high-paid sector. Likewise, the boundary worker between middle and low-paid sectors is lower in the larger, 
more productive city, and for the same reason.

Final goods are assembled CES from the high- and low-paid intermediates and a composite of the middle-paid intermediate and a purchased intermediate that can alternately be considered as an imported intermediate or a fully-depreciating capital good produced from the final good. Importantly, the purchased intermediate is a relative substitute for the middle-paid intermediate and a relative complement for the high and low-paid intermediates.

We have five principal theoretical results, two in the cross section and three in comparative statics. The first shows that when the strength of city-level comparative advantage of the large, productive city in the high relative to middle-paid sector is sufficiently strong, then the fraction of employment of the large city in the middle-paid sector will be smaller than in the small city. This matters because local exposure to sectors has had a prominent role in discussions of the corresponding impact of shocks. The second provides technical conditions on the distribution of location types within cities that leads the distribution of skills across cities to be log-supermodular.

The next three results consider the consequences of a drop in the price of the purchased intermediate, which consistent with the literature can equivalently be thought of as an offshoring or a routinization shock. The first key comparative static is that labor market polarization will take place both in the aggregate and in each city. The second key comparative static result concerns comparisons of job adjustments by sector in the large versus small cities. Given sufficiently strong comparative advantage of the large city in the high relative to the middle-paid sector, (i) the percentage point decline in middle-paid jobs will be larger in the large city; (ii) the percentage point growth in high-paid jobs will be greater in the large city; and (iii) the percentage point growth in low-paid jobs will be smaller in the large city. The third key comparative static concerns which middle wage jobs are vulnerable in the large versus small city. In the large city the strong loss of middle wage jobs will be among the higher-middle-paid jobs and vice versa in the small city.

An interesting feature of the model is that the strength of city-level comparative advantage matters for both levels and comparative statics results. Of these, perhaps less surprising is that the strength of comparative advantage of the large relative to the small city in high relative to middle-paid sectors matters for the relative shares of jobs in the middle-paid sector. To understand the connection between this comparative advantage restriction and the comparative statics results requires a few steps. The first step is that, due to this city-level comparative advantage, in the large relative to the small city the skill cutoff between sectors will at both margins be lower in the large city than the small. The second step relies on the individual level patterns of absolute advantage, which is concave, linear, and convex as we move from low to middle to high-paid sectors. It is then the interaction of these features that yields that adjustment to a common shock will be stronger in the high-paid jobs in the large city and in the low-paid jobs in the small city. Intuitively, faced with a common price shock, the larger city is in a more elastic region at the boundary of high and middle-paid jobs and the reverse at the boundary of middle and low-paid jobs. 
In the context of the model, labor market polarization in the aggregate and in each city is dealt with directly by the first comparative static result. The great divergence in the model comes from combining our cross sectional result on log-supermodularity, so that the larger city initially is relatively specialized in the high-paid sector, with our comparative static result that this same city will see the largest percentage point gains in high-paid jobs. Finally, it is worth noting that under the conditions specified, and in contrast to much discussion in the literature, we also provide conditions under which the greatest total loss in middle-paid jobs will be in the large city that is initially less exposed to these jobs.

\subsection{Setting and Key Empirical Findings}

We examine the predictions of our theory based on observations from French cities for the period 1994-2015. Plant-level observations on occupations, wages, and individual characteristics are aggregated from the commune to the city level, corresponding to the demands of the theory. To the extent possible, we rely on approaches from prior work to categorize occupations as low-, middle, or high-paid and to characterize the degree to which occupations are offshorable or routinizable. We consider the 117 French cities with population above 50,000 and study these individually and grouped by size.

Our empirics provide considerable support for the theoretical predictions of our model. As model validation, we find that the distribution of skills across cities of different sizes in France is consistent with log-supermodularity. Furthermore, large cities have a larger share of high-paid jobs and a smaller share of middle and low-paid jobs. Labor market polarization occurs both in the aggregate and in cities across the size distribution. In the period considered, the percentage point loss of middle-paid jobs was greater in large cities, this by a factor of roughly two in the largest relative to the smallest cities. The increase in jobs that replaced these middle-paid occupations was stronger in high-paid relative to low-paid jobs in the large relative to the small cities. In the largest cities, this was roughly two high-paid jobs for each low-paid job, and the reverse in small cities. Consistent with the great divergence, it was the large cities, already most specialized in high-paid jobs, that had the largest rise in high-paid jobs in the study period. Initial exposure to middle-paid jobs was not a good predictor of the loss of middle-paid jobs, since the large cities started the period with the lowest exposure to these jobs yet also had the largest percentage point decline there. It is true that exposure to the most routinizable and offshorable jobs was a good predictor of the loss specifically of those jobs. However exposure to these jobs was not a good predictor of the aggregate loss of middle-paid jobs. The greater loss of middle-paid jobs in large cities, consistent with our theory, corresponded principally to the loss of upper-tier middle-paid jobs in those cities. 


\subsection{Related Literature}

Our work builds on a number of literatures. Labor market polarization is documented in the United States in Acemoglu (1999), Autor et al. (2006), and Autor and Dorn (2013); and in European countries in Goos and Manning (2007) and Goos et al. (2009). Acemoglu and Autor (2011, 2012) provide an extended discussion of why recent periods should be investigated in frameworks consistent with labor market polarization. Autor and Dorn (2013) provide a canonical model incorporating what can be thought of as routinization or offshoring shocks. Cortes (2016) introduces a continuum of labor types mobile across tasks, so is able to accommodate polarization at both the high and low ends, as well as to provide a rich model of the variability of wage shocks among those who remain in their initial task versus changes in tasks both up and down.

An important literature has explored spatial dimensions of labor market polarization via the impact of shocks on local labor markets. Prominent examples include Autor et al. (2013) and Acemoglu and Restrepo (forthcoming). These papers have focused on relating job loss to the exposure of these local labor markets to the most offshorable or routinizable occupations, or alternatively to robots. In his recent Ely lecture, Autor (2019) explores empirically how some impacts of labor market polarization have varied across areas of different densities in the United States.

The term "great divergence" was first applied to cities by Moretti (2012) and has been closely linked to models of skill-biased technical change. The roots of this literature may be found in a seminal paper by Katz and Murphy (1992) and receives its fullest treatment in Goldin and Katz (2009). These works focus on what they term the race between technology and education. In these settings, there is ongoing skill-biased technical change. In periods in which the relative supply of skills rises sufficiently rapidly, the matching of relative demand and supply shocks leaves the skill premium unaffected. When skill-biased technical change outpaces the rise in the relative supply of skill, the skill premium rises. Important contributions to research on the great divergence have included Diamond (2016), Eckert (2019), Ganong and Shoag (2017), Giannone (2017) and Cerina et al. (2019). Harrigan et al. (2018) examine the role of Hicks neutral and skill-biased technical change on the level and composition of jobs at French firms for the period 2009-2013.

Our work is also related to a literature on heterogeneous labor and firms in spatial equilibrium across a system of cities. This includes Behrens et al. (2014), Davis and Dingel (2019, 2020), and Gaubert (2018). Some of these also build on Costinot (2009) and Costinot and Vogel (2010).

Our work here draws on various facets of these literatures. In order to link up to the labor market polarization literature, we go beyond a skilled-unskilled labor dichotomy. We focus on a setting with three key tasks and a continuum of labor, where routinization and offshoring activities substitute for middle-paid labor and complement low- and high-paid labor. This also allows us to have polarization at both high and low skill ends, and in our setting with many cities also to have polarization both in the aggregate and in all locations. Since we are focused on long run equilibria rather than transitional dynamics, we allow all skills to choose a location and a sector 
without frictions. We focus on the important concept of local exposure to the posited shocks, considering both in theory and data whether this provides a robust indication of vulnerability to these shocks. Our framework seeks to unify the literatures on labor market polarization and the great divergence, so relies on the routinization and offshoring shocks in the former rather than the skill-biased technical change shocks common in the latter. In doing so, our paper focuses on how the polarization shocks translate into different evolutions in large and small cities. Relative to the prior literature on heterogeneous labor in spatial equilibrium, we simplify in some dimensions and enrich in others. Where the prior literature focused on conditions for symmetry breaking, we take these as given in our baseline model to focus on new elements. We also emphasize the role not only of individual- but also city-level relative productivities across tasks. All of these considerations allow us to formulate hypotheses at the aggregate and city levels that we take to data.

Section 2 of our paper develops our theoretical framework. Section 3 describes our data. Section 4 examines key cross-sectional features of the data. Section 5 considers labor market polarization both in the aggregate and within individual and groups of cities. Section 6 examines the link between initial exposure to sectors and shocks to those sectors. Section 7 concludes.

\section{Theory}

In this section, we build a model integrating the core framework of job polarization in Autor and Dorn (2013) with the system of cities model of Davis and Dingel (2020). ${ }^{1}$ The resulting equilibrium matches key features of the data. First of all, it predicts a log-supermodular distribution of skills across cities. Second, when the price of capital or offshored tasks decreases, polarization of the job market occurs both in the aggregate and in each city. Furthermore, we provide conditions under which the labor market polarization is stronger (a magnitude effect) and biased in favor of high-paid jobs in the large city ( a reallocation effect) despite an initially lower share of exposure to middle-paid jobs. The key condition is that skills matter sufficiently more in high-paid occupations and that the comparative advantage of high-paid workers in the large city is sufficiently strong.

\section{$2.1 \quad$ The environment}

Let us consider an economy populated by households that provide heterogenous labor, consume, and decide where to live and work. Households consume housing services and a final good that is produced using labor and a capital/offshoring good. To produce non-degenerate distributions for skills and sectors across cities, we allow for different locations in each city so that households with the same skill can be indifferent between a better location in the small/less productive city or a

\footnotetext{
${ }^{1}$ The model features a long run full spatial equilibrium in which all workers freely choose a sector of production and a location. We thus look at comparative steady states rather than transition dynamics, which is beyond the scope of this paper.
} 
worse location in the large/more productive city.

Locations. The set of cities is $c \in\{1,2\} .^{2}$

In each city, there is a continuum of locations $\tau \in[0, \infty) . \tau$ denotes the distance from an ideal location inside a city. This can be interpreted in a variety of ways, including as commuting distance to a central business district, or as remoteness from the core of a productive cluster with positive but spatially decaying spillovers. As will become clear, having multiple locations within a city allows us to introduce a trade-off between living in a better location in a smaller and less productive city or in a worse location in a larger and more productive city. ${ }^{3}$

In each city $c$, we assume that the supply of locations $\{t \mid t \leq \tau\}$ is $S(\tau)$ with $S(0)=0, S($. strictly increasing and twice continuously differentiable.

Households. Households consume a single final good and 1 unit of housing.

Each household inelastically provides 1 unit of labor. Households have different skills that we denote by $\omega . \omega$ is distributed on $[\underline{\omega}, \bar{\omega}]$ with a pdf $n($.$) and \underline{\omega} \geq 1$.

They freely choose where they live (the city $c$ and the internal location $\tau \geq 0$ ). We denote the rental price of location $(c, \tau)$ by $r(c, \tau)$. We use the price of the final good as the numeraire and we normalize the price of unoccupied locations to 0 so that $r(c, \tau) \geq 0$. Locations are owned by absentee landlords who spend their rental income on the final good.

Households can also decide in which sector $\sigma$ they work. Finally, we denote by $f(\omega, \sigma, c, \tau)$ the endogenous pdf of the distribution of households $\omega$ across sectors $\sigma$ and locations $f(c, \tau)$.

Production. Production in this economy involves different sectors: final goods are produced out of intermediate goods $\{h, m, l, Z\}$. Goods $\{h, m, l\}$ are produced with labor and the capital/offshoring intermediate good $Z$ is produced with, or traded for, the final good. All goods are traded with zero transportation costs except non-traded housing.

Final goods. The final good is produced by a continuum of identical competitive firms. To produce, they use intermediate goods $\{h, m, l\}$ as well as $Z$.

The production function of the representative firm is:

$$
Q=\left(a(h) q(h)^{\gamma}+\left(a(m) q(m)^{\frac{1}{\theta}}+a(z) Z^{\frac{1}{\theta}}\right)^{\gamma \theta}+a(l) q(l)^{\gamma}\right)^{1 / \gamma}
$$

where $q(j)$ and $p(j), j \in\{h, m, l\}$, are the quantity and the price of intermediate good $j, p_{z}$ is the price of capital and/or an offshoring intermediate input with the rest being technological parameters

\footnotetext{
${ }^{2}$ We extend our framework to $N$ cities in the Online Appendix B.2.

${ }^{3}$ As this will be clearer, locations within a city differ in terms of workers' productivity. Our model is homeomorphic to one where locations would differ in terms of commuting costs. For further interpretations of the location $\tau$ and the connection with other models of cities in the literature, see Davis and Dingel (2020).
} 
that we assume to be fixed. As in Autor and Dorn (2013), we assume that capital/offshoring goods are relative substitutes with intermediate goods produced by the middle-paid sector $(m)$ but they are relative complements with the the intermediate goods produced by the high-paid sector $(h)$, that is $\gamma<\theta$. In contrast with Autor and Dorn (2013), there is only one production function in the aggregate and no local ones: this implies that there are no local complementarities either through production or demand between the low-paid sector and the rest of the economy of the city. Yet the demand for the low-paid sector input $(l)$ can increase due to its complementarity with the other input at the aggregate level. Finally, note that we assume without loss of generality that the elasticity of substitution is the same for the low- $(l)$ and the high-paid $(h)$ sectors. $^{4}$

As we are using the final good as numeraire, the profits of the representative firms can be written as:

$$
\Pi=Q-p(h) q(h)-p(m) q(m)-p(l) q(l)-p_{z} Z
$$

Intermediate goods. The intermediate goods $\{h, m, l\}$ are produced with a constant returns to scale technology using only labor. There is one sector to produce each of the $\{h, m, l\}$ goods. Consistently, we label sectors by $\sigma \in\{h, m, l\}$ where $h$ stands for high paid, $m$ for middle paid and $l$ for low paid.

Each individual with skill $\omega$, living in city $c$ and in a location $\tau$ has a productivity:

$$
H(\omega, \sigma, c) T(\tau)
$$

On this productivity, we make the following assumptions. First, $T($.$) is a decreasing function$ identifying the cost in productivity of being remote from the most productive location in a city. Second, $H(\omega, \sigma, c)$ is log-supermodular in $(\omega, \sigma)$ and $H(., \sigma, c)$ is increasing. As a result of logsupermodularity in $(\omega, \sigma), H(\omega, m, c) / H(\omega, l, c)$ and $H(\omega, h, c) / H(\omega, m, c)$ are increasing functions of $\omega$. On top of this assumption, we assume that $H$ is such that skills matter much more for the highpaid occupation than for any other sectors. This amounts to assuming that $H(\omega, h, c) / H(\omega, m, c)$ is sufficiently more convex than $H(\omega, m, c) / H(\omega, l, c)$. To capture this idea simply, we assume that $H$ has the following functional form:

Assumption 1 (Functional form of productivity). In city $c$, the productivity of an agent with

\footnotetext{
${ }^{4}$ This assumption implies no loss of generality as our results can be extended to any situation where a decline in the price of the capital goods leads to an increase in the relative low- and high-paid sectors' inputs $p(l) / p(m)$ and $p(h) / p(m)$. As we detail later, our model also contrasts with Autor and Dorn (2013), as we eliminate immobility across locations, for unskilled labor, or sectors, for skilled labor.
} 
productivity $\omega$ where $1 \leq \underline{\omega} \leq \omega \leq \bar{\omega}$ is:

$$
\begin{aligned}
H(\omega, l, c) & =A(l, c) \omega^{\phi} \text { with } \phi \in(0,1), \\
H(\omega, m, c) & =A(m, c) \omega, \\
H(\omega, h, c) & =A(h, c) e^{\eta \omega} \text { with } \eta=1 / \underline{\omega} .
\end{aligned}
$$

To provide more intuition on this functional form, we plot in Figure 1 value marginal products in the three sectors as a function of $\omega$ and for given intermediate input prices. A similar assumption can be found in Autor and Dorn (2013) where skills matter relatively more for the middle-paid sector compared with the low-paid sector. More generally, this captures the idea that a marginal variation in skill is of modest importance for low-paid occupations; becomes more important in middle-paid occupations; and is key in high-paid occupations. ${ }^{5}$

In the interest of simplicity, we make the assumption of exogenous productivity differences between the two cities. Such differences may naturally arise endogenously in this type of framework, but that is not the focus of this paper. ${ }^{6}$

Assumption 2 (Absolute and comparative advantages). City 1 has an absolute advantage in all sectors:

$$
A(j, 1)>A(j, 2) \text { for } j \in\{l, m, h\}
$$

and a comparative advantage in higher-paid sectors:

$$
\frac{A(h, 1)}{A(h, 2)}>\frac{A(m, 1)}{A(m, 2)}>\frac{A(l, 1)}{A(l, 2)}
$$

The absolute advantage in Assumption 2 directly implies that $H(\omega, \sigma, 1) \geq H(\omega, \sigma, 2)$ for all $(\omega, \sigma)$. In equilibrium, this will lead city 1 to be larger than city 2 .

Finally, we assume that there is perfect competition in all the three sectors so that in each sector the wage per efficiency unit of labor equals the price of the intermediate good $p(\sigma)$.

\footnotetext{
${ }^{5}$ The role of these technological assumptions may be clarified by considering how productivity rises as skill rises from that of one of this paper's co-authors $\omega$ to that of Albert Einstein at $\omega^{\prime}>\omega$. In low skill tasks, such as pushing a broom, skill raises productivity, but in a concave fashion. Even Einstein will be only so much better at pushing a broom. In middle skill tasks, such as being a patent clerk, skill raises productivity in a linear fashion. Einstein will thus be a much better patent clerk. In high skill tasks, such as theoretical physics, skill raises productivity in a convex manner. Einstein will be vastly better at theoretical physics. Naturally the allocation of skills to tasks within a city depends on the returns to skills in each of these tasks within a city, as illustrated by the upper envelope of returns in Figure 1. This is consistent with the approach to superstars of Rosen (1981).

${ }^{6}$ Davis and Dingel $(2020,2019)$ provide alternative approaches to endogenous productivity differences across cities in a symmetry breaking setting. In appendix B.1, we provide a way to obtain endogenous productivity differences consistent with the patterns of labor market polarization. The productivity differences may also stem from exogenous differences in the comparative advantage of locations.
} 
Capital good/offshoring intermediate good The intermediate good $z$ is produced by transforming final goods using the following technology:

$$
Z=\frac{1}{\xi} q
$$

where $q$ is the amount of final goods and $\xi$ is a technology parameter. There, perfect competition implies:

$$
p_{z}=\xi
$$

The intermediate good $z$ has two interpretations. The first is that it is a capital good that substitutes for middle-paid labor as in Autor and Dorn (2013). Note that as in Autor and Dorn (2013), this capital good would fully depreciate with production. With this view, $\xi$ is a parameter that governs the efficiency of producing the capital good. The second interpretation is that $Z$ is an imported intermediate and $\xi$ is the terms of trade. As a result, a drop in $p_{z}$ could be either due to routinization, a drop in the price of computer capital, or due to offshoring, a drop in the domestic price of the intermediate import due to technical progress abroad or the removal of trade barriers.

\subsection{Household decisions}

Let us first investigate location and sector decisions by agents and how these decisions depend on factor prices, $p(l), p(m)$ and $p(h)$.

The utility flow obtained by an agent with skill $\omega$, location decisions $(c, \tau)$ and intermediate good sector $\sigma$ is:

$$
H(\omega, \sigma, c) T(\tau) p(\sigma)-r(c, \tau)
$$

We are interested in understanding in which city and in which sector a household with skill $\omega$ decides to work, that is, how the household maximizes (6) with respect to $c, \tau$ and $\sigma$.

Sectoral decisions. In each city $c$, we can define two thresholds $\omega(m, c)$ and $\omega(h, c):^{7}$

$$
\begin{aligned}
& H(\omega(m, c), m, c) p(m)=H(\omega(m, c), l, c) p(l) \\
& H(\omega(h, c), h, c) p(h)=H(\omega(h, c), m, c) p(m)
\end{aligned}
$$

The threshold $\omega(m, c)$ is such that a household in a given city $c$ is indifferent between working in the low-paid and the middle-paid sectors and the threshold $\omega(h, c)$ is such that the same household is indifferent between the middle- and the high-paid sectors.

\footnotetext{
${ }^{7}$ Note that these thresholds do not depend on the location $\tau$ as the productivity term $T(\tau)$ is separable.
} 
The following lemma shows that these two thresholds are sufficient for characterizing sectoral decisions by households, breaking the skills into three intervals according to the intermediate sector those skills specialize in:

Lemma 1. A household living in city $c$ and with skill $\omega$ works in sector $l$ when $\omega \leq \omega(m, c)$, in sector $m$ when $\omega \in(\omega(m, c), \omega(h, c))$ and in sector $h$ when $\omega \geq \omega(h, c)$.

Across cities, these thresholds satisfy:

$$
\omega(h, 1)<\omega(h, 2) \text { and } \omega(m, 1)<\omega(m, 2)
$$

\section{Proof. See Appendix D.1}

The differences in the thresholds across cities result from the comparative advantage of the larger cities in higher-paid sectors associated with the increasing importance of individual skills in higher-paid sectors. For the same prices of intermediate goods, the same individual is relatively more productive in higher-paid sectors in the larger city and, thus, has more incentive to work in these sectors. Accordingly, in the larger city the least skilled worker in the high-paid sector is less skilled than the counterpart in the smaller city. A similar ranking holds for the least skilled worker in the middle-paid sector between the two cities.

Let us note that, in principle, it is possible that a sector does not exist in at least one of the two cities, even though the production function guarantees that this sector should exist in at least one city. This happens, for example, when $\omega(m, 1) \leq \underline{\omega}$. In this case, there is no low-paid sector in city 1. In what follows, we focus on situations where the three sectors are in both cities. ${ }^{8}$

In the end, Lemma 1 defines a function $M$ such that $M(\omega, c)$ is the optimal sectoral decision for a household with skill $\omega$ in city $c$.

Location decisions. Let us now turn to location decisions. First note that a household with skill $\omega$ decides to work in city 1 and in location $\tau$ only if it is not better off working in the other city or in any other location $\tau^{\prime}$, that is:

$$
\max _{\sigma, \tau} H(\omega, \sigma, 1) T(\tau) p(\sigma)-r(1, \tau) \geq \max _{\sigma^{\prime}, \tau^{\prime}} H\left(\omega, \sigma^{\prime}, 2\right) T\left(\tau^{\prime}\right) p\left(\sigma^{\prime}\right)-r\left(2, \tau^{\prime}\right)
$$

When this holds with equality the skill $\omega$ is present in the two cities.

\footnotetext{
${ }^{8}$ This result contrasts with Davis and Dingel (2020) where the sectors $(\sigma)$ and skills $(\omega)$ in the less productive city were a strict subset of the sectors and skills in the larger city. This comes from the assumption that the productivity gains in a given city are different depending on the sector $(A(\sigma, c)$ is a function of $\sigma)$. In the case where these gains are constant across sectors $(A(\sigma, c)=A(c))$, the thresholds would be the same in the two cities, thus yielding the same results as Davis and Dingel (2020). In addition, note that different thresholds also imply that the same skill $\omega$ does not need to produce in the same sector $\sigma$ in the two cities even when present in both.
} 
Location within cities. Let us start by describing the location decision within each city. Note that the set of locations occupied in city $c$ is a bounded set. We denote by $\bar{\tau}(c)$ the maximum value of $\tau$ occupied in city $c$. More desirable locations have higher rental prices:

Lemma 2. Housing prices $r(c, \tau)$ are decreasing on $[0, \bar{\tau}(c)]$ and $r(c, \bar{\tau}(c))=0$. Finally, for all $\tau \in[0, \bar{\tau}(c)]:$

$$
S(\tau)=L \int_{0}^{\tau} \int_{\sigma} \int_{\omega} f(\omega, M(\omega, c), c, x) d \omega d \sigma d x
$$

Proof. See Appendix D.2

Furthermore, higher skill households occupy more desirable locations. We find this by obtaining a mapping between skill $\omega$ and location $(c, \tau)$ :

Lemma 3. There exists a function $K$ such that: $f(\omega, M(\omega, c), c, \tau)>0 \Leftrightarrow K(c, \tau)=\omega$. The function $K(c,$.$) is continuous and strictly decreasing.$

In addition, when the low-paid sector exists in both cities, $\bar{\tau}(1)$ and $\bar{\tau}(2)$ are such that $K(2, \bar{\tau}(2))=$ $K(1, \bar{\tau}(1))=\underline{\omega}$. Furthermore, $K(1,0)=\bar{\omega}(1)=\bar{\omega}$ and there exists $\bar{\omega}(2)$ such that $K(2,0)=\bar{\omega}(2)$.

Finally, city 1 is larger than city $2(\bar{\tau}(1)>\bar{\tau}(2))$.

Proof. See Appendix D.3

Lemma 3 implies that when the low-paid sector is in both cities the least skilled person $\underline{\omega}$ is also in both cities in location $\bar{\tau}(1)$ in city 1 and in location $\bar{\tau}(2)$ in city 2 so that city 1 's set of skills is a strict superset of that in city 2 .

Due to the absolute advantage of city 1 in all sectors, we also obtain that $\bar{\tau}(1)>\bar{\tau}(2)$ : the least skilled person lives in a worse location in city 1 than in city 2. An additional implication is that city 1 , the most productive city, is also the largest city. This justifies referring to city 1 as the large city and to city 2 as the small city.

Using the results of Lemma 1 and 3, we can connect location decisions with the sectoral decisions and show that more skill intensive sectors concentrate in the most attractive locations in the city.

Lemma 4 (Sorting within cities). In each city $c$, there exists $\bar{\tau}(h, c)$ and $\bar{\tau}(m, c)$ satisfying $\bar{\tau}(h, c) \leq$ $\bar{\tau}(m, c) \leq \bar{\tau}(c)$ such that:

- If $\omega \geq \omega(h, c)$ then $\tau \leq \bar{\tau}(h, c)$,

- If $\omega \in[\omega(m, c), \omega(h, c)]$ then $\tau \in[\bar{\tau}(h, c), \bar{\tau}(m, c)]$,

- If $\omega \leq \omega(m, c)$ then $\tau \in[\bar{\tau}(m, c), \bar{\tau}(c)]$.

In particular, $f(\omega, \sigma, c, \tau)=0$ for all $\omega, \sigma, c$ and $\tau \geq \bar{\tau}(c)$.

Proof. See Appendix D.4 
Locations across cities. There are locations in city 1 where the productivity of workers is strictly higher than what it could be in city 2. This happens for locations $\tau$ where productivity in city 1 strictly exceeds what can be obtained in city 2 even in city 2's best location. More formally:

$$
H(\omega(\tau), M(\omega(\tau), 1), 1) T(\tau)>H(\omega(\tau), M(\omega(\tau), 2), 2) T(0)
$$

where $\omega(\tau)=K(1, \tau)$ is the value of $\omega$ occupying location $\tau$ in city 1 . This defines a maximum value for the skill present in city $2, \bar{\omega}(2)$, for which equation (12) holds with equality.

Below the productivity $\bar{\omega}(2)$, for each $\omega$ and for each $\tau$, there exists $\tau^{\prime}<\tau$ such that the productivities in city 1 and in city 2 are the same:

$$
H(\omega(\tau), M(\omega(\tau), 1), 1) T(\tau)=H(\omega(\tau), M(\omega(\tau), 2), 2) T\left(\tau^{\prime}\right)
$$

To give further intuition, when there are high-paid workers in both cities and when $\omega(h, 1) \geq$ $\omega(m, 2),(13)$ can be rewritten, depending on the value of the skill $\omega$ as:

$$
\begin{array}{rcl}
\forall \omega \in[\omega(h, 2), \bar{\omega}(2)], & A(h, 1) T(\tau) & =A(h, 2) T\left(\tau^{\prime}\right) \\
\forall \omega \in[\omega(h, 1), \omega(h, 2)], & A(h, 1) T(\tau) e^{\eta \omega} p(h) & =A(m, 2) \omega T\left(\tau^{\prime}\right) p(m) \\
\forall \omega \in[\omega(m, 2), \omega(h, 1)], & A(m, 1) T(\tau) & =A(m, 2) T\left(\tau^{\prime}\right) \\
\forall \omega \in[\omega(m, 1), \omega(m, 2)], & A(m, 1) T(\tau) \omega p(m) & =A(l, 2) T\left(\tau^{\prime}\right) \omega^{\phi} p(l) \\
\forall \omega \leq \omega(m, 1), & A(l, 1) T(\tau) & =A(l, 2) T\left(\tau^{\prime}\right)
\end{array}
$$

In the end, for an $\omega \leq \bar{\omega}(2)$ and a $\tau$, there exists a single $\tau^{\prime}$ in city 2 . This defines a function $\Gamma(\omega, \tau)=\tau^{\prime}$, which identifies a location in city 2 at which factor $\omega$ has the same return as it would have in city 1 at $\tau$. Spatial equilibrium thus implies that for all $\omega$ present in both cities:

$$
H(1, \omega, M(\omega, 1)) T(\tau)=H(2, \omega, M(\omega, 2)) T(\Gamma(\omega, \tau))
$$

In equilibrium, in the location $\tau$, if the agent with skill $\omega$ is the marginal buyer, we then have that:

$$
r(1, \tau)=r(2, \Gamma(\omega, \tau))
$$

In Davis and Dingel (2020), the function $\Gamma$ would be constant with respect to $\omega$, but, as the larger city has also a comparative advantage in higher-paid sector, we obtain the following result:

Lemma 5. For all $\omega, \Gamma(\omega,$.$) is continuously increasing in \tau$ and, for any $\tau, \Gamma(., \tau)$ is continuous and weakly decreasing in $\omega$.

Proof. See Appendix D.5 
In the end, for $\omega \in[\underline{\omega}, \bar{\omega}(2)]$, households are indifferent between a less desirable location in the more productive and larger city 1 or a more desirable location in the less productive and smaller city 2. Figure 2 summarizes the distribution of skills across sectors and cities.

Sectoral decisions and factor prices. As this can be observed from equations (7) and (8), the two thresholds are functions of intermediate good prices $p(l), p(m)$ and $p(h)$. The following lemma clarifies how these thresholds move as a function of the relative prices $p(m) / p(h)$ and $p(l) / p(m)$ :

Lemma 6. A decline in $p(m) / p(h)$ implies a relatively larger decline for $\omega(h, 1)$ than for $\omega(h, 2)$. An increase in $p(l) / p(m)$ implies a relatively larger increase in $\omega(m, 2)$ than for $\omega(m, 1)$.

Proof. See Appendix D.6

A crucial assumption to obtain Lemma 6 is the one of the relative convexity of $H(\omega, l, c)$, $H(\omega, m, c)$ and $H(\omega, h, c) .{ }^{9}$ Let us explain why by focusing on the threshold between high-paid and middle-paid jobs, $\omega(h, c)$. The comparative advantage of the large city in the high-paid sector leads this threshold to be smaller in the large city as shown by Lemma $1(\omega(h, 1)<\omega(h, 2))$. Actually, the larger is this comparative advantage, the lower will be the threshold $\omega(h, 1)$ compared with $\omega(h, 2)$, as $H(\omega, h, c) / H(\omega, m, c)$ is an increasing function of $\omega$.

Through our assumptions, the relative productivity between the high- and the middle-paid sectors $(H(\omega, h, c) / H(\omega, m, c))$ is a convex function of the skill $\omega$. As a result, a decline of the relative price of middle-paid sector's good leads to a stronger decline of $\omega(h, 1)$ than of $\omega(h, 2)$ as the former is a region where the relative productivity is flatter. Using other words: the incentive for a middle-paid worker to become a high-paid worker increases for a larger set of skills in the large than in the small city. We illustrate this point in Figure 3 in the special case where $A(m, 1)=A(m, 2)$.

In the end, the comparative advantage of the large city in the high-paid sector leads both to a lower threshold $\omega(h, c)$ in that city but also to a stronger decline of this threshold in the case of a decline of the price of the capital/offshored good.

Similarly, the incentive for a middle-paid worker to become a low skill worker also increases in both cities. $H(\omega, m, c) / H(\omega, l, c)$ being an increasing function of $\omega$, Lemma 1 shows that $\omega(m, 1)<$ $\omega(m, 2)$. However, $H(\omega, m, c) / H(\omega, l, c)$ is a concave function of $\omega$, thus leading $\omega(m, 2)$ to increase by more than $\omega(m, 1)$ for the same variation of the price of the capital/offshored good.

Figure 4 summarizes these findings.

Evolution with respect to comparative advantage and convexity. Let us have a few words about how the results of Lemma 6 evolve as a function of the comparative advantage of the two cities in the different sectors and as a function of the convexity assumptions on productivities.

\footnotetext{
${ }^{9}$ So far, we have not used this assumption but only the fact that these two ratios were increasing functions of the skill $\omega$.
} 
Let us start with the threshold between the high-paid and the middle-paid sectors. In some of our results, we are going to focus on situations where the productivity in the high-paid sector in city 1 $(A(h, 1))$ is large. The relative stronger decline of $\omega(h, 1)$ compared with $\omega(h, 2)$ is more pronounced when the slope of productivity in the high-paid sector $(\eta)$ is larger and/or when the comparative advantage in the high-paid sector in the large city is stronger $(A(h, 1) / A(h, 2)$ as compared with $A(m, 1) / A(m, 2))$. As a result, a high productivity $A(h, 1)$ results in a lower threshold $\omega(h, 1)$ so that this threshold ends up in a region that is even flatter. An implication is then that a decrease in the price of the middle-paid sector input has even more stronger downward effect on $\omega(h, 1)$ when $A(h, 1)$ is large.

Conversely, the relative increase of $\omega(m, 2)$ compared with $\omega(m, 1)$ is more pronounced when the slope of productivity in the low-paid sector $(\phi)$ is greater and/or when the comparative advantage in the low-paid sector in the small city is stronger $(A(l, 2) / A(l, 1)$ as compared with $A(m, 2) / A(m, 1))$. In particular, when $A(l, 2) / A(l, 1)$ is very close to $A(m, 2) / A(m, 1), \omega(m, 2)$ behaves as $\omega(m, 1)$.

\subsection{Implications}

We are now able to describe the main implications of our model. To start with, we describe the distribution of skills and sectors across cities. Then we investigate the effect of a labor market polarization shock (a decline in the price of the capital/offshoring good $p_{z}$ ) both in the aggregate and across cities. Finally, we provide further description of what happens to middle-paid jobs and to high-paid ones. In particular, we show that a labor market polarization shock can contribute to the great divergence across cities.

\subsubsection{Allocation of skills and city exposure to the middle-paid sector}

Let us first describe the allocation of skills and the exposures to different sectors across cities.

Initial exposure to middle-paid jobs Our first implication is about the exposure of a given city to middle-paid jobs, that is the share of total jobs in the middle-paid sector:

Proposition 1. When $\frac{A(h, 1)}{A(h, 2)}$ is sufficiently large relative to $\frac{A(m, 1)}{A(m, 2)}$, the share of middle skill sector jobs is smaller in the larger city.

Proof. See Appendix D.7.

The lower exposure of the large city to middle-paid jobs reflects this city's comparative advantage in high-paid jobs. Indeed, the relative importance of the three different sectors in the larger city depends on the relative productivity gains of concentrating in that city households working in each of these sectors. When the productivity gains of concentrating workers in the high-paid sectors in the large city are sufficiently large, the share of this sector becomes relatively large and crowds out 
the presence of the other sectors, thus leading the larger city to be more exposed to high-paid jobs and less exposed to middle-paid jobs.

Log-supermodularity Our second implication concerns the distribution of skills across the two cities. To this purpose, let us introduce the supply of locations within a city:

$$
V(z)=-\frac{\partial}{\partial z} S\left(T^{-1}(z)\right)
$$

This function indicates the number of locations within a city with $\tau=T^{-1}(z)$. We can now obtain the following proposition:

Proposition 2. Assume that the supply of locations in each city $V(z)$ has a sufficiently decreasing elasticity. Then, the distribution of skills $f(\omega, c)$ is strictly log-supermodular.

Proof. See Appendix D.8

Recall that a distribution is strictly log-supermodular when, for $c>c^{\prime}$ (i.e. city $c$ is larger than city $\left.c^{\prime}\right)$ and $\omega>\omega^{\prime}, f(\omega, c) f\left(\omega^{\prime}, c^{\prime}\right)>f\left(\omega, c^{\prime}\right) f\left(\omega^{\prime}, c\right)$, which means that there are relatively more high skill workers in the larger city.

Given our previous result in Proposition 1 where we obtained conditions under which the share of middle-paid jobs is smaller in the larger city, we can also characterize the elasticity of the middlepaid jobs with respect to the size of the city:

Corollary 1. Under the conditions of Proposition 1, the elasticity for middle-paid jobs with respect to the size of the city is lower than 1.

One implication of this result, associated with the fact that larger cities have a lower initial share of middle-paid workers as shown in Proposition 1, is that occupations, in contrast to skills, do not need to be log-supermodular. More specifically, the total number of jobs in the middle-paid occupations may be lower in the larger city compared with the smaller city.

Share of low-paid jobs across cities Given Lemmas 1 and 3 and the log-supermodularity result we can state:

Corollary 2. The share of low-paid workers is lower in the larger city.

\subsubsection{Labor market polarization in the aggregate and across cities}

Let us now investigate how a decrease of the price of the intermediate good $z$ affects the distribution of jobs in our economy, as in Autor and Dorn (2013). To start with, let us clarify the effect of a shock to the price of capital/offshoring intermediate goods on the relative prices of the middle-paid sector with the high- and the low-paid sectors: 
Lemma 7. A decline in $p_{z}$ leads to a decline of the relative prices of the middle-paid sector good: $p(m) / p(h)$ and $p(m) / p(l)$.

Using this pattern of the relative price, let us investigate how the shock to $p_{z}$ affects the labor markets in the two cities.

Labor market polarization in the aggregate Let us first observe how this decline of the price of capital affects labor markets overall and in each city. From Lemma 6, we can infer that middle-paid jobs decline at both margins in both cities. This leads to the following proposition:

Proposition 3. A decline in $p_{z}$ reduces the share of middle-paid jobs in the aggregate and in each city.

Proof. See Appendix D.9.

As in Autor and Dorn (2013), a decline in the price of capital goods/offshoring intermediate goods leads firms to substitute middle-paid jobs by capital. This leads workers to reallocate, either to the high-paid or to the low-paid sectors, depending on workers' skills and, overall, the labor market becomes more polarized. ${ }^{10}$

Importantly, this polarization does not only occur in the aggregate, as already shown by Autor and Dorn (2013), but also in each city.

Labor market polarization across cities Still, labor market polarization features some striking differences depending on the size of the city. The decline of middle-paid jobs and the magnitude of the rise in low- and high-paid jobs depends on the relative productivity gains of the different sectors in the different cities.

Proposition 4. When $\frac{A(h, 1)}{A(h, 2)}$ is sufficiently large relative to $\frac{A(m, 1)}{A(m, 2)}$, then a decline in $p_{z}$ implies that in the large relative to the small city:

(i) The decline in middle-paid jobs is larger in percentage points.

(ii) The increase in high-paid jobs is larger in percentage points.

(iii) The increase in low-paid jobs is smaller in percentage points.

Proof. See Appendix D.10.

\footnotetext{
${ }^{10}$ Cortes (2016) studies the effects of labor market polarization in the aggregate in a model with occupational sorting driven by the comparative advantage of higher skilled in more complex tasks as in Gibbons et al. (2005). Three occupational groups ranked by ability (non-routine manual; routine and non-routine cognitive) are taken into account. As a result of increased automation those with highest ability switch to non-routine cognitive jobs while those with low ability to non-routine manual jobs. These predictions are borne out in PSID data. Indeed those with highest skills switch into non-routine cognitive occupations the most.
} 
Under the conditions of Proposition 4, labor market polarization is then not uniform across cities. More precisely, it differs both in terms of magnitude and in terms of reallocation. In terms of magnitude, the shock to middle-paid jobs is stronger in larger cities. ${ }^{11}$ In terms of reallocation, adjustment following the shock is tilted towards high-paid jobs in the large city, and the opposite in the small city.

Let us provide some intuition for these results. The decrease in the price of capital/offshored goods corresponds to a negative demand shock for middle-paid jobs. As shown in Lemma 6, such a decline leads, on the one hand, to a stronger decrease in the threshold $\omega(h, 1)$ than in $\omega(h, 2)$ : households have a stronger incentive to shift to the high-paid sector in the large city than in the small city due to the comparative advantage of the large city in the high-paid sector. On the other hand, the threshold $\omega(m, 1)$ increases by less than $\omega(m, 2)$ : the incentive to shift to the low-skill sector increases by more in the small city.

As discussed above, the effects of a price decline of capital/offshored goods are driven by technological assumptions: the job market evolutions will depend on the strength of the comparative advantage of one city in a sector.

In the case where the comparative advantage of the large city in the high-paid sector is large enough, ie. $A(h, 1) / A(h, 2)$ is sufficiently large relative to $A(m, 1) / A(m, 2)$ - and, by transitivity, $A(l, 1) / A(l, 2)-$, the first effect dominates. Not only are more high-paid jobs created in the large city, but also more middle-paid jobs are destroyed there. There is a rise in low-paid jobs in the large city, but of a lesser magnitude than of high-paid jobs.

However, for the same reason, this lower magnitude is also a function of comparative advantages: the more concave is productivity in the low-paid sector and/or the smaller is the comparative advantage of the small city in the low-paid sector $(A(l, 2) / A(l, 1)$ compared to $A(m, 2) / A(m, 1))$, the smaller is the difference in the evolution of low-paid jobs across cities.

Another consequence of a large comparative advantage of the large city in the high-paid sector is to squeeze the low-paid sector. As a result, one could consider a limit case in which the large city might contain no low-paid jobs.

Remark. We have obtained proposition 4 as an asymptotic result on the comparative advantage of the large city for the high-paid jobs in a context where productivities are relatively more elastic to skills for these high-paid jobs. In this way, our result does not depend on the skill distribution $(n()$.$) .$

In the case of low-paid jobs, an alternative way to obtain a stronger increase in the small city would be to assume a sufficiently strong comparative advantage of the large city in middle-paid jobs, i.e. $(A(1, m) / A(2, m)$ large enough compared to $A(1, l) / A(2, l)) .{ }^{12}$

\footnotetext{
${ }^{11}$ Given that the initial exposure to middle-paid jobs is lower in large cities, their percentage decline there is higher as well.

${ }^{12}$ In our current approach, the large city comparative advantage in higher-paid jobs leads to a squeezing of low-paid jobs.
} 
Remark. Note that our results are driven by technological assumptions that do not require agglomeration economies - the technological parameters $A(., c)$ need not be functions of the city-level population or its composition. However, our results would be reinforced if the comparative advantage of the large city in the high-paid sector is an increasing function of the share of high-paid jobs (see Online Appendix B.1).

\subsubsection{The effect of labor market polarization on middle-paid jobs.}

Let us investigate further the consequences of labor market polarization on middle-paid jobs. Our first important result is that the initial exposure to these jobs is not a predictor of the strength of their destruction. We then investigate which middle-paid jobs are destroyed and how this evolves across cities.

Initial exposures to middle-paid jobs and labor market polarization Combining the result of Propositions 1 and 4 leads to the following corollary:

Corollary 3. The destruction of middle-paid jobs is the largest in percentage points in the large city where there is, initially, the lower share of middle-paid jobs.

Exposure is not the key driver that explains the destruction of middle-paid jobs. Our interpretation is that technology or offshoring are necessary ingredients for the destruction of middle-paid jobs but they are not sufficient and one also needs to think about incentives to destroy these jobs. In our model, the incentives to destroy middle-paid jobs depend on city characteristics and the opportunity cost of keeping these jobs rather than creating new ones in other sectors.

A direct implication of Corollary 3 is that we cannot instrument future job destruction only by city-level exposures or any other feasibility constraints for these destructions.

The heterogeneity among middle-paid jobs across cities Given that exposure is not the key driver of middle-paid job destruction, we further address the nature of middle-paid jobs destroyed in large and small cities.

As in the low- and high-paid sectors, workers occupying middle-paid jobs are heterogeneous with respect to their skills - they have different values for $\omega$. It is then possible to further analyze how labor market polarization affects middle-paid jobs across cities depending on workers' skills. In this paragraph, we show that, in large cities, it is the most skilled (i.e. with the highest $\omega$ or, equivalently, with the highest wage) middle-paid jobs that are destroyed and replaced by high-paid jobs. In small cities, it is mainly the least-skilled middle-paid jobs that are destroyed and replaced by low-paid jobs.

To this purpose, we split middle-paid jobs into high-wage and low-wage ones. Given that nominal wages in the model are functions of the skill $\omega$, it is equivalent to splitting middle-paid 
jobs into higher-middle-paid and lower-middle-paid jobs. Let $\hat{\omega}$ be the threshold between these two categories. To avoid having empty sets, $\hat{\omega} \in[\omega(m, c), \omega(h, c)]$ for $c \in\{1,2\}$. With this threshold in hand, we can define higher wage middle-paid workers as the workers working in the $m$ sector with a skill higher than $\hat{\omega}$ and the ones with a skill lower than $\hat{\omega}$ are lower skilled.

Proposition 5. The share of higher wage middle-paid jobs decreases by more in percentage points in the large city.

The share of lower wage middle-paid jobs decreases by more in percentage points in the small city.

Proof. See Appendix D.11.

What stands behind this proposition is the relative behavior of the thresholds $\omega(h, c)$ and $\omega(m, c)$ across cities. These thresholds correspond to the indifference condition between, respectively, the high- and the middle-paid sectors and the middle- and the low-paid sectors. As shown by Lemma 6 , the upper threshold $\omega(h, c)$ decreases by more in the large city (city 1) and the lower threshold $\omega(m, c)$ increases by more in the small city (city 2 ). As a result, more higher wage middle-paid jobs are destroyed in the large city following a labor market polarization shock while more lower wage middle-paid jobs are destroyed in the small city.

Remark. In the current discussions (see Autor, 2019), most of the concerns on the consequences of technology and offshoring are concentrated on the outcomes of workers shifting from the middle- to the low-paid sector. An important conclusion on middle-paid workers in our model can be inferred from Cortes (2016). In relative terms, workers that remain in the middle-paid sector face a larger income shock compared with middle-paid workers that shift to either the low-paid or high-paid sectors. However, some workers initially in the middle-paid sector that shift to the low-paid sector may face a lower income decline compared with some workers initially in the middle-paid sector that shift to the high-paid sector. This is not a general rule. It is only a caution that one cannot apportion workers into gainers and loser purely be the average wage of the sector into which they move.

\subsubsection{The effects on high-paid jobs and the great divergence}

Let us now turn to what happens to high-paid jobs. Our main conclusion concerns the great divergence across cities.

The great divergence In the end, the decline in the price of capital/offshored goods leads to a reinforcement of the specialization of the largest city in high-paid jobs. It is the large city with the lowest exposure to middle-paid jobs (and more specialized in high-paid jobs, as noted by Proposition 1) that further increases the high-paid jobs' share and reduces the number of middle-paid jobs. A direct implication from Proposition 4 is then: 
Corollary 4. The share of high-paid jobs increases by more in larger cities, which have an initially larger share of high-paid jobs.

This finding is consistent with the great divergence as described by Moretti (2012): large cities that were already more abundant in terms of high-paid jobs had these jobs grow faster. Importantly, here, the great divergence arises due to the labor market polarization shock: by being skewed towards higher-paid jobs in larger cities, labor market polarization contributes to make larger cities even more abundant in higher-paid jobs.

Note that the prediction of a great divergence in Corollary 4 stands in contrast to a key spatial equilibrium result of Autor and Dorn (2013). In their model, the only source of regional variation is the routine task intensity of production of the local Armington traded good (hence also a lower highskill intensity for that good). Regions whose local good has a high routine task intensity attract few high skilled workers and so are both smaller and relatively unskilled. This cross-sectional correlation between city size and skills is consistent with the data. A routinization shock that lowers the price of computer capital, in their framework, would then attract high skilled workers to the smaller less-skilled cities where previously they were scarce (their result iv, p. 1568). We could label this prediction the great convergence. This prediction is directly opposite to ours and also stands in opposition to the observations of Moretti (2012) and the evidence presented below of a great divergence.

Supply and a demand shock to high-paid jobs What is the effect of labor market polarization on the wages of high-paid occupations? In Autor and Dorn (2013), the number of workers occupying high-paid jobs is assumed to be fixed. Thus, their wages are necessarily increasing: the labor market polarization shock is thus only a positive demand shock on high-paid labor given that this labor is a complement to capital. In our setting, this complementarity remains, but the possibility to shift to the high-paid sector also implies that more workers enter into the high-paid sector. As a result, the demand shock on high-paid labor is potentially mitigated by the increasing supply for these jobs, so that the price of the high-paid good $p(h)$, and so the wage in the high-paid sector, can either increase or decrease. A similar conclusion holds true for the low-paid sector that also faces both a demand and a supply shocks of workers. Nevertheless, the relative prices $p(m) / p(l)$ and $p(m) / p(h)$ both always decrease, which is key for the results on labor market polarization.

Let us now confront the predictions of our model with data from France on the period 1994-2015. In Section 3, we describe the different datasets that we are using and we report in Sections 4, 5 and 6 the evidence on the distribution of skills, labor market polarization, and the great divergence in France. 


\section{Data description}

We focus on a few key questions. We examine the characteristics and the evolution of labor market polarization in the aggregate and by metropolitan area, as well as the log-supermodularity of skills. These require specific data on job characteristics (e.g. their routine or offshorable nature), hours worked, and wages by occupation. We also need a measure of skills such as educational attainment. The data should be geographically detailed at the metropolitan level and comparable over time. French administrative data and the Censuses satisfy these requirements.

\subsection{DADS-Postes data}

Our main data source is DADS-Postes for the years 1994-2015, which is a part of the publicly available DADS ("Déclaration Annuelle des Données Sociales") data set. ${ }^{13}$ This data is provided by INSEE, the French national statistical institute, and is based on mandatory annual reports by all French companies. ${ }^{14}$ It includes data about all legally held job positions ("postes"), detailed at the plant level. The initial year 1994 is chosen as this is the first year of data that has comprehensive coverage of hours worked while 2015 was used as the last vintage available. For each worker, for a particular job position, the main reported data are the hours worked, remuneration (total compensation before taxes), occupation type, age and gender. ${ }^{15}$ Establishment location is available at the commune level, the lowest administrative unit. There were 36,169 communes in metropolitan (mainland) France as of January 1, 2015.

We use data only for private companies (those that are incorporated and have the legal category starting with "5" in the INSEE classifications), excluding privatized firms or those that changed status from public to private incorporation (which impacts for example the public or private law under which labor contracts are offered) in the period 1994-2015. ${ }^{1617}$ We use data for mainland France (without Corsica or the overseas departments). We limit the sample to workers 25-64 years of age. To minimize erroneous entries (for example employees recorded with few working hours

\footnotetext{
${ }^{13}$ The French Labor Survey is available since 1982 but for early years has approximately 60,000 observations per year and has only data at the department level. This allows to document some general facts about labor market polarization starting from 1982, but the DADS-data is exhaustive and gives inter alia more geographical details.

${ }^{14}$ This includes public and private firms. Data on self-employed are not reported prior to the late 2000s.

${ }^{15}$ We cannot observe education data or job tenure, and it is not possible to aggregate incomes by individual workers at each year level (for 1994) nor to follow them through time.

${ }^{16}$ Some firms in the finance, insurance and real estate sectors reported pre-2001 their employees from branches at few establishments for example at the department level. This represents a small fraction of employment in these sectors based on INSEE assessments on 2001-2003 data and may introduce minor errors given the scale of the problem when we use metropolitan area-level data. Exclusion of these sectors from our analysis does not change our results considerably and does not impact our conclusions. We include Table E.19 without these sectors as a replication of Table 5 in a robustness test.

${ }^{17}$ DADS-Postes has data on public sector employment only since the end of the 2000s. The evolution of public sector employment based on Census data for years 1990-2015 is in the Online Appendix E.8. Public sector employment increased in metropolitan France by 0.5 percentage points in the period and its evolution does not reveal systematic spatial nor high- middle- or low-skill patterns confounding our analysis.
} 
with abnormally high income) one needs to filter the job positions. We retain all positions where there were at least 120 hours worked in a year. ${ }^{18}$

\subsection{Occupations and classification into wage groups}

In DADS-Postes the information on occupations is available at a 2-digit level according to the French occupation classification called PCS ("Nomenclature des professions et categories socioprofesionnelles"). French statistical authorities developed it to classify occupations according to their "socio-professional" status and there is not an exact correspondence at this level to other internationally used classifications such as e.g. the International Standard Classification of Occupations (ISCO).

The broad 1-digit codes represent CEOs or small-business owners (CS category "2"), "cadres" (high-paid professionals, code "3"), intermediate professions (codes starting with "4"), low-paid employees (codes with " 5 " as the first digit) and blue-collar workers (codes starting with "6"). The 2-digit categories provide more detail, allowing us to use 18 different CS 2-digit categories (see Table E. 4 for representative occupations within each category). ${ }^{19}$ We exclude artisans (CS 21 and 22), agriculture-related (CS 10 and CS 69) and public-sector occupations (CS 33, 34, 42, 45, 52 and CS 53 employed in the public sector).

As a measure of exposure to automation we use the Routine Task Intensity (RTI) index employed by Autor and Dorn (2013) (based on the RTI measure of Autor et al. (2003)), classifying occupations according to the ease of their automation. For the measure of offshorability, we use the index developed by Goos et al. (2014) based on actual offshoring patterns, which identifies occupations readily substituted by imports. To translate these indices and obtain exposure to automation and offshoring at the 2-digit CS level used in DADS, we proceed as follows. We first merge the exposure classifications of Goos et al. (2014) (that include RTI in their dataset) based on 2-digit ISCO occupation classification into the 1994 French Labor Survey. Then we map their ISCO-based values into the 2-digit CS ones used in French data basing on ISCO occupations' hours shares in the 2-digit CS. ${ }^{20}$ In this index, the CS category 54 (office workers) is most routine and 67 (unskilled industrial workers) is most offshorable. The top 4 highest-paid occupations are among the least routinizable and offshorable.

The list of 2-digit CS categories we use is provided in Table 1 along with a short description, their in-sample employment share, average wages in our sample of cities in 1994 and 2015, as well

\footnotetext{
${ }^{18}$ We do not observe, however, a material difference in our results if no filtering is applied or filtering based on end-of-year presence with at least 30 days in the firm. INSEE provides filtering in the DADS data set, but it is not consistent between 1994 and 2015.

${ }^{19}$ See Caliendo et al. (2015) for the use of CS 1-digit categories to analyse firms' hierarchies. Firms should report their data using much finer 4-digit codes, but many fail to do so especially before 2003. During the 2003 revision of codes a new category, 31 ("liberal" professionals such as lawyers etc.), previously included in CS 37, was created. In all our data we merge the two together.

${ }^{20}$ The ISCO and CS categories are both available only in the French Labor Survey and not directly in the DADS data. More details in the Online Appendix E.1.
} 
as the routine occupation (RTI) and offshorability (OFF-GMS) ranking from Goos et al. (2014). The exact index values for each category are given in the Appendix Table E.2.

Consistent with the broad labor market polarization literature, the model focuses on three tasks with different levels of skill and pay. Matching theory and data thus necessitates mapping a richer set of occupations into three wage categories. Given that this tripartite division is just a heuristic for thinking about the data, there will no unique way to do this and any division will almost of necessity be imperfect. That said, the categorization may matter substantively for the empirics, so requires justification.

Labor market polarization is defined as the decline of middle-paid jobs along with the growth of high- and low-paid jobs. Following Autor and Dorn (2013) and Goos et al. (2014), we take the mean wage by occupation in the initial year of our data, here 1994, as a primitive ordering of our set of 18 occupations. Forming the wage-occupation groups then requires criteria for the division into high-, medium-, and low-wage groups that respects this ordering.

Figure 6 provides a visualization of occupational growth between 1994-2015. Only four occupations had declines of 1 percentage point or more of total employment in this period. These four are (from high to low wage) CS 48 supervisors and foremen, CS 46 mid-level professionals, CS 62 skilled industrial workers, and CS 67 unskilled industrial workers. The same four occupations each had their share of total employment decline by 34-47 percent in this period. No other occupations had comparable declines in absolute or proportional terms in this period. On its face, these declines alone would provide a justification for including these four in a study of job declines in this period, hence making the relevant interval of middle-paid jobs from CS 48 supervisors and foremen to CS 67 unskilled industrial workers as those vulnerable to the posited shocks.

This definition of the middle-paid group thus also implicitly defines high- and low-paid groups. The implied high-wage group includes CEOs and small business owners, as well as highly paid professionals ("cadres"), all of which have both high wages and a distinct social status. The implied low-wage group includes all 2-digit occupations for which the Labor Survey of hours in 1994 had at least half of hours in what Goos et al. (2014) identified as low-wage occupations.

An alternative that we could consider is whether an ordering based on the PCS 1-digit codes might make a reasonable partition into the wage groups. The codes CS2 for CEOs and small business owners and CS3 for high paid professionals, if combined into the high-paid sector, would indeed yield the same boundary between high- and middle-paid occupations as in our visualization exercise. And, indeed, in terms of the individual occupations this would also correspond to a wage gap of 21 percent between the lowest paid CS3 and highest paid CS4 occupations. Adding CS4 occupations to the high-paid group would be consistent with a single cut between high-paid and other occupations, but it would have two downsides. As noted, it would require bridging the 21 percent wage decline at the boundary of the 2-digit CS3 and CS4 occupations. Moreover, that would put in the high wage group two of the occupations (CS 46 and 48) whose jobs declined most 
sharply in absolute and relative terms in our period of study, hence be inconsistent with the spirit of the labor market polarization approach. In sum, using the 1-digit PCS codes suggests the same boundary between high- and middle-paid occupations as our simple visualization exercise.

Trying to use the remaining 1-digit CS codes 4, 5, and 6 to define a boundary between middleand low-paid groups immediately runs into problems. The 2-digit CS5 and CS6 occupations have no clear ordering by initial mean wage, so cannot sensibly be separated. If they are combined as the low-paid sector, then this would include two of the sectors with the largest absolute and relative job declines, CS 62 and 67, in the low-paid sector. Again, this is against the spirit of the labor market polarization approach. ${ }^{21}$

Taken together with our prior observations, this suggests that our initial approach, focusing on encompassing within the middle-paid group those occupations with the largest absolute and proportional job declines is likely to be the best approach to defining our occupation-wage groups. Thus, from before, we define the high-paid group as the four highest paid occupations, the lowpaid group as the four lowest-paid occupations, and middle-paid occupations as all others. The boundaries of the middle-paid group are CS 48 supervisors and foremen at the top and CS 67 unskilled industrial workers at the bottom.

Given that the labor market polarization approach hypothesizes that the shocks of interest are routinization and offshoring, it makes sense to examine how the middle-paid group thus defined is characterized in terms of exposure to these forces. While we would not like to define the wagegroups to target these measures, it would be disturbing if the groups we do define are directly at odds with our hypothesis. An examination of the rankings shows that all five of the most routinizable and offshorable occupations are situated in our middle-paid group. ${ }^{22}$ This includes the highest paid of these, CS 48 supervisors and foremen, which is 3rd in both routinizability and offshorability. It also includes the lowest paid in the middle-paid occupations, CS 67 unskilled industrial workers, which ranks 2 nd in routinizability and 1st in offshorability. The median rankings for routinizability and offshorability in the middle-paid group is thus 6 and 5.5 respectively, and the corresponding numbers are 8.5 and 13 for the low-paid group and 15.5 and 13.5 in the highpaid group. This suggests that the typical middle-paid occupation is indeed more routinizable and offshorable (see Online Appendix Table E.3 for calculations based on actual indices). That said, these relations are not mechanical, as one can note by the fact that the middle-paid sector does have some sectors that score poorly on routinizability or offshorability. Taken together, this again suggests the reasonableness of the partition into wage groups we have suggested.

One nonetheless could wonder if this is an excessively expansive definition of middle-paid jobs encompassing nearly three-quarters of all jobs in 1994 and more than three-fifths in 2015. We have

\footnotetext{
${ }^{21}$ Our main results are not materially affected when we move the border between low- or middle-paid occuptions. For example, such robustness checks for the comparison of means of changes in occupation shares between small and large cities of Tables 5 - are shown in Online Appendix Tables E.15 and E.16.

${ }^{22}$ In the Online Appendix, a plot of resulting RTI and OFF-GMS measures for the considered occupations is shown in Figure E. 2 while Table 1 with these values is reproduced as Table E.2.
} 
already argued that this is a reasonable partition for a variety of reasons. We would add, moreover, that this selection of the middle-paid occupations, wide though it is, is actually well-suited to our approach linking labor market polarization and the great divergence. Our theory focuses attention on differences of large and small cities in which middle-paid jobs are at risk, and so having a sufficiently wide interval of middle paid jobs makes possible an evaluation of these predictions.

In more detailed discussions e.g. in Section 6 we will divide middle-paid jobs into subcategories. We will refer to the group of CS 48, 54, 62 and 67 as the most routine and offshorable (MRO) jobs as they have lowest routinizability and offshorability rankings. They comprise $40.9 \%$ of hours worked in 1994 in our private-sector employment sample and span the entire wage distribution of middle-paid jobs. Other middle-paid jobs are either still quite routine or offshorable, especially in comparison to high-paid jobs. For example, CS 63 (skilled manual workers) or 65 (transport and logistics personnel) are both ranked as relatively routine/offshorable and CS 46 is 6th ranked in terms of offshorability. They also may be likewise vulnerable indirectly through their hierarchical connections to MRO jobs (e.g. CS 46, middle managers) or become more routinizable/offshorable with time (e.g. for CS 46: photographers, graphic designers, translators or secretaries; see also Appendix $\mathrm{C}$ for a theoretical explanation). We refer to these non-MRO middle-paid occupations as other middle-paid (OMP) jobs.

\subsection{Cities considered and final sample}

For most of our empirical exercises, we focus on cross-city comparisons. We thus examine data on jobs performed in cities (metropolitan areas) above 50,000 inhabitants as of 2015 unless otherwise noted. We aggregate the commune-level data to the metropolitan area level ("unité urbaine") with city boundaries defined by INSEE as of 2010 unless otherwise indicated. There are 117 such cities in 2015 with the largest 55 above 100,000 inhabitants. ${ }^{23}$. The characteristics of the final sample are given in Table 2.

These cities above 50,000 inhabitants encompass $54 \%$ of the total population of metropolitan France in $2015^{24}$. In 2015, these jobs account for $73 \%$ (73.4\% in 1994) of wages paid and $68.4 \%$ (68.9\% in 1994) of hours worked in the mainland in the non-farm private sector. In 1994 and 2015 respectively, firms active in these cities for which we have data account for 396,637 (out of 596,368) and 633,851 (out of 998,467) firms. Noting exclusions as above, we retain a sample that accounts for $65 \%$ of total wages paid and $58 \%$ of hours worked in metropolitan France in 1994 and 2015 with data from 364,482 and 596,446 firms in these years respectively. ${ }^{25}$

\footnotetext{
${ }^{23}$ They are shown in Online Appendix Figure E.1 and population data by city category in Table E.1

${ }^{24}$ In robustness checks we also consider urban areas ("airés urbaines") as defined by INSEE encompassing all communes in the metropolitan area ("unité urbaine") plus all communes where at least $40 \%$ of residents have employment in the same metropolitan area. The urban areas including the metropolitan areas that we consider account for $70 \%$ of the total population.

${ }^{25}$ Establishment-level output data is unavailable in the French data.
} 
We consider up to the cities into six major categories of cities for our analysis. Paris, given its size $(10.7 \mathrm{~m}$ inhabitants in the metropolitan area and $37.5 \%$ of jobs in 2015 in our final sample) is a category by itself. Then, we use 2 categories of cities above $0.5 \mathrm{~m}: 0.5-0.75 \mathrm{~m}$ and $0.75 \mathrm{~m}$ and above (except Paris). Such a choice is warranted because there is a considerable size difference between the seventh largest metropolitan area - Bordeaux (904 thousand inhabitants) and the eighth Nantes (634 thousand people). Moreover, cities with metropolitan areas of " $0.75 \mathrm{~m}$ and above" have also "urban areas" ("airés urbaines") as defined by INSEE of over 1m inhabitants. For other divisions we follow the ones of INSEE: $0.2-0.5 \mathrm{~m}$ (size categories "71" and "72") , 0.1-0.2m (sizes "61" and "62") and $0.05-0.1 \mathrm{~m}$ ("51" and "52"). We took the city size of 50,000 as a cutoff for our main discussion, although dropping this to 20,000 doesn't materially affect our results. Throughout the studied period city populations increased by $9.9 \%$ on average. There are no significant differential changes in the sizes of cities e.g. when one compares cities with population above $0.5 \mathrm{~m}$ with the rest or smallest cities $<0.1 \mathrm{~m}$.

\subsection{Other data}

We also use other data sources to provide additional statistics. To examine log-supermodularity, we use the detailed part of the Census of 1999 (5\% of population), also provided by INSEE. It was the most comprehensive Census within the main sample period that provided data on education, nationality of respondents, and allows us to identify their location at the commune level. We also use the less-detailed 1990 and 2013 Censuses to document the evolution of e.g. educational attainment across cities. Population data was taken from the INSEE for the Census years and $2015 .^{26}$

\section{Cross-sectional patterns}

We start our empirical investigation by understanding key cross-sectional patterns in the data that are suggested by our theory. We document the log-supermodularity of skills in city size, and show that the shares of the three broad occupational categories across cities conform with our theory. Throughout, we will look at either groups of cities or individual city data to show that our results hold.

\subsection{Log-supermodularity of skills}

Proposition 2 provides conditions, as in Davis and Dingel (2020), under which the distribution of skills $f(\omega, c)$ is log-supermodular in city size. To obtain a measure of skills we turn to the 1999

\footnotetext{
${ }^{26}$ Population for 1994 at the commune and therefore city level is unavailable. Hence, whenever we use weighting we use 1990 population from the Census.
} 
Census, which has the best data on both diplomas and commune of residence among the Censuses spanning our time period. We measure skills by the highest diploma received by individuals. The results are illustrated in Figure 5 (further results in Online Appendix Tables E.7-E.11). As expected, Figure 5 shows there is an ordering of the population elasticities of skills, with the two lowest skill groups having an elasticity statistically significantly below 1; two middle skill groups (with high school diplomas and some college) having an elasticity insignificantly different from 1; and a high skill category of workers with a graduate diploma that has a significant population elasticity of 1.18. These observations carry over when we consider only French-born individuals; the presence of low-paid immigrants does not change these patterns. ${ }^{27}$ This provides a baseline confirmation of the appropriateness of our model and allows us to state

Fact 1 (Log-supermodularity of skills). The distribution of skills is log-supermodular in city size.

\subsection{Occupation shares across cities}

We now turn to occupation share patterns that can be obtained from the detailed DADS data on hours worked. As indicated in the theory section, people with the same skills may perform different occupations depending on the city where they choose to reside, and this has implications on the observable employment shares across cities. ${ }^{28}$

In Table 3 we can observe the share of high-, middle-, and low-paid occupations in total employment across our six categories of cities in 1994 and 2015. This Table uses the DADS-Postes data set for 1994 and 2015 and calculates hours worked in different occupations across metropolitan areas.

The share of high-paid occupations in total employment increases monotonically with city size in both years, as implied by our Corollaries 1 and 2. The differences are sizeable, especially when comparing the extremes - the Paris metropolitan area and cities with population between 0.050.1m. In both 1994 and 2015, the fraction of high skill jobs in Paris was roughly three times as high as in cities of $0.05-0.1 \mathrm{~m}$ population. Given the overall rise in skilled jobs, this gap rose from 15 percentage points to 25 percentage points.

The share of the middle-paid jobs monotonically declines with city size in line with Proposition 1 in both 1994 and 2015. The share of the lowest-paid occupations is highest in the smallest cities

\footnotetext{
${ }^{27}$ We also confirm these results using our classification of high, middle and low-paid jobs and the broad 1-digit CS categories in Online Appendix Tables E.9-E.10. It is not a coincidence that the population elasticity coefficients for high-paid jobs and "cadres" (respectively 1.14 and 1.16) are similar: "cadres" perform the bulk of high-paid occupations. The coefficients on middle- and low- paid jobs that are below 1 (in a statistically significant manner) show that larger French cities have not only fewer low-paid jobs, but also fewer middle-paid jobs. This conforms with Corollary 1. Similar patterns in terms of population elasticities for the same 4 diploma categories can be obtained from the 1990 and 2013 Censuses (not shown), confirming the notion that log-supermodularity of skills holds for French cities over the entire studied period.

${ }^{28}$ In Online Appendix Table E.5 we show the joint distribution of diplomas and occupation categories in 1990 in the Census data. The distribution of higher-skill requiring diplomas is correlated with occupations ranked by wages.
} 
in either of the years, although the cross-city variation is modest. ${ }^{29}$

In Table 4 we also confirm these observations by comparing the means of occupational shares among the 11 largest cities in our sample $(>0.5 \mathrm{~m}$ inhabitants) and 62 smallest cities $(0.05-0.1 \mathrm{~m}$ inhabitants). Observing the first three columns of that Table, it is clear that the differences in the shares of high-, medium- and low-paid jobs across cities of different sizes are statistically different from one another and agree with our theory. ${ }^{30}$

This allows us to state:

Fact 2 (Occupation shares). In larger cities, the share of high-paid jobs is larger and the share of middle- and low-paid occupations is smaller.

Overall these patterns, along with evidence on log-supermodularity, support the cross-sectional implications of our theoretical model under the noted conditions. ${ }^{31}$

\section{$5 \quad$ Labor market polarization}

We now document the evolution of labor markets across cities over the period 1994-2015 to assess the implications of our model. Our primary aim is to understand how labor market polarization manifests itself distinctly across cities of different sizes.

In this section, we establish that labor market polarization happened not only in the aggregate, but also in individual cities and groups of cities. We then examine how cities' characteristics affect the local nature of labor market polarization. In particular, we show that polarization led to an increase in the share of high-paid jobs in large, already highly-skilled cities — consistent with the great divergence.

\subsection{Labor market polarization in France.}

We first investigate how employment evolved in mainland France in the aggregate over the period 1994-2015. Defining labor market polarization, again, as a fall in the employment share of medium-paid occupations and a rise in the share both of high- and low-paid ones, we find that this occurred in France in the period 1994-2015. In 1994, the high-, medium-, and low-paid occupations, respectively account for one-eighth, three-quarters, and one-eighth of employment, rising to roughly one-fifth, three-fifths, and one-fifth in 2015.

We examine these changes in overall employment shares in Table 1. The share of middle-paid jobs declined from $75.6 \%$ to $61.1 \%$ between 1994-2015. The bulk of job losses in this category

\footnotetext{
${ }^{29}$ The decline of low-paid occupation shares with city size is, however, clear when one measures the share of hours worked for the three lowest paid jobs (sales-related occupations, personal service workers and unskilled manual workers; see Online Appendix Table E.24).

${ }^{30}$ For rank-correlation statistics that reinforce these patterns see Online Appendix Table E.28.

${ }^{31}$ They also contradict, for France, the extreme-skill complementarity hypothesis advanced by Eeckhout et al. (2014).
} 
occurred in the MRO jobs - the 4 most automation and offshoring exposed occupations (supervisors and foremen; office workers; skilled and unskilled industrial workers), and their share in hours worked fell from $40.9 \%$ to $28.9 \%$. The only other occupation experiencing a large overall employment share drop was mid-level associate professionals (CS 46), the share of which fell from $12.3 \%$ to $7.6 \%$ in the labor force. It is ranked 6th highest in our classification of offshorable categories. At the same time, the overall shares of high- and low-paid jobs increased respectively from $12.9 \%$ to $20.6 \%$ and from $11.6 \%$ to $18.3 \%$.

The patterns detailed at the 2-digit CS-level are exhibited in Figure 6 and confirm for France in the years 1994-2015 the U-shaped relationship studied by Autor et al. (2006) and Autor and Dorn (2013) for the U.S. and documented by Goos and Manning (2007), Goos et al. (2009) and Goos et al. (2014) for Europe. ${ }^{32}$ They are also consistent with observations made by Harrigan et al. (2016) for France for the time period 1994-2007.

So, whether we look at high-, medium- or low-paid jobs (as done in Goos et al. (2014)) or occupations ranked by wages (as in Autor and Dorn (2013) or Harrigan et al. (2016)), we obtain the following fact:

Fact 3. Over the period 1994-2015, the French labor market became more polarized in the aggregate.

Proposition 3 holds that labor market polarization is induced by increased automation or a lower offshoring cost. This is compatible with the above patterns.

\subsection{Labor market polarization in large and small cities}

Our theory has implications on the evolution of labor markets across cities of different sizes that we investigate next.

Labor market polarization in individual cities. Figure 7 depicts labor market evolution at the individual city level for all cities in our sample. Three key features emerge. The first is that labor market polarization is close to ubiquitous. All 117 largest cities in France experienced a decline in employment of middle-paid jobs over the period 1994-2015. In 115 of these 117 cities this was accompanied by a contemporaneous increase in the share of both low- and high-paid occupations at the city labor market level. Second, size is systematically related to the decline in middle-paid jobs, with larger cities losing more of these jobs. Third, size is likewise systematically related to the types of jobs that replace these middle-paid jobs. In large cities, the replacement jobs are skewed toward high-paid jobs, in small cities toward low-paid jobs.

\footnotetext{
${ }^{32}$ We exclude here the category of CEOs - CS category 23. It is an outlier with highest pay that has a rather constant population elasticity in sample - its employment share varies between $0.8 \%$ and $1.1 \%$ in 1994 among the 6 city groups. The change in the share is less than 0.3 percentage points in absolute terms across cities in the given years.
} 
These city-size patterns are easier to visualize if we group cities into three categories: large (above $>0.5 \mathrm{~m}$ of inhabitants, 11 cities), medium (44 cities between 0.1-0.5m inhabitants) and small (62 cities between $0.05-0.1 \mathrm{~m}$ ), by summing the hours worked in each job category. The corresponding changes in job shares are plotted in Figure 8. Consistent with Proposition 3, labor market polarization occurs not only in the aggregate but also for all city sizes. We get the same pattern if we look at occupation share changes between 1994 and 2015 for 6 city categories in Table 3 or for largest and the smallest cities in Table $5 .^{33}$

No matter the size of the city, we observe that middle-paid jobs were destroyed over the period and high- and low-paid jobs became more abundant.

We make thus the following observation:

Fact 4. Over the period 1994-2015, the French city-level labor markets became more polarized.

Labor market polarization across cities. Figure 7 shows clearly that the labor market developments vary systematically across individual cities and by city size. Figure 8 shows more compactly how the patterns of polarization differ markedly across the city sizes. To start, the magnitude of the destruction of middle-paid jobs is stronger in large cities. This is confirmed in the second panel of Table 3, where we see the evolution of the share of middle-paid jobs across six city sizes. ${ }^{34}$ We see that the percentage point decline in employment shares of middle-paid occupations is sharpest in the largest cities. In Paris, over the period 1994-2015, the middle-paid jobs share declined by 20 percentage points. In contrast, this decline was much lower in smaller cities, e.g. only 12 percentage points in metropolitan areas between 50 and 100 thousand inhabitants, and this is true in spite of the lower initial exposure to middle-paid jobs in larger cities. If we consider this in proportional terms, the decline of middle-paid jobs in Paris was twice as large (31\%) as in the smaller cities (15\%).

Next, in Table 5 we compare the means of share changes across occupations in large and small cities. We observe a higher destruction overall of middle-paid jobs (by 18.1 percentage points on average) in cities of over $0.5 \mathrm{~m}$ in comparison with the smallest cities (11.6 percentage points). ${ }^{35}$ The tests confirm that the destruction of middle-paid jobs is monotonically increasing with city size. This leads to the following fact:

Fact 5 (Magnitude effect). Labor market polarization led to more destruction of middle-paid jobs in large cities.

This finding is consistent with our model, in which Proposition 4 provides conditions under which middle-paid jobs decline the most in large cities.

\footnotetext{
${ }^{33}$ Online Appendix Tables E.12-E.19 show robustness checks for the same changes and growth patterns as in Table 5 using different samples: without Paris, including smaller cities with population between 0.02-0.05m, without the FIRE industries, etc. We also confirm this finding using 2-digit CS categories in Figure E.3.

${ }^{34}$ One can observe a similar pattern using 2-digit CS categories as shown by Figure E.3 in the Appendix.

${ }^{35}$ In Online Appendix Table E.27 rank correlations between city size and middle-paid job destruction are also statistically significant.
} 
Not only do larger cities have a sharper percentage point decline in middle-paid jobs, but the pattern of reallocation differs between large and small cities. This is demonstrated in Figure 8, where the reallocation of jobs is more tilted towards high-paid jobs in large cities and towards low-paid jobs in smaller cities.

This finding is confirmed for six city groups in Table 3 (first and third panels for high- and low-paid jobs respectively). More precisely, this Table shows that the percentage point increase in high-paid jobs is also monotonic in metropolitan area size. In Paris and metropolitan areas above $0.75 \mathrm{~m}$ inhabitants the increase in such occupations is above 10 percentage points over the period 1994-2015. The smallest cities (0.05-0.1m of population) have the lowest gain, less than 4 percentage points. Although the variation is more modest, the percentage point increase in low-paid jobs is highest for the smallest cities. These observations are reinforced by individual city evidence in rank correlation tests as reported in Online Appendix Table E.27, and in comparisons between large and small cities as in Table 5.

When quantifying the difference between Paris and the smallest cities in Table 3 or large and small cities in Table 5, one would find that, in the large city, for every middle-paid job destroyed, $2 / 3$ will be created in the high-paid sector and $1 / 3$ in the low-paid sector. In small cities, the proportions are reversed, with $1 / 3$ created in the high-paid sector and $2 / 3$ created in the low-paid sector.

Overall, all this evidence points in the same direction: the creation of high-paid (low-paid) jobs is increasing (decreasing) with a city's size. We obtain:

Fact 6 (Reallocation effect). Labor market polarization led to relatively more creation of high-paid jobs in large cities and of low-paid ones in small cities.

As with Fact 5, this is also consistent with Proposition 4.

The Great Divergence. In our theory, an implication of Proposition 4 is the so-called great divergence as described by Moretti (2012). This implication is formalized by Corollary 4, which notes conditions under which high-paid jobs increase by more in the large cities that feature an initially larger share of these jobs. Table 3 provides the basic relation, where large cities have both the higher initial share of high skill workers and the larger percentage point increase in these workers. This is further confirmed in Tables 4 and $5 .{ }^{36}$ This can also be visualized in Figure 7: large cities represented by red dots tend to have experienced a larger increase in the share of high-paid jobs. Figure 8 confirms these patterns for three city groups.

We can state:

Fact 7 (Great Divergence). The share of high-paid jobs has increased the most in larger cities where this share was initially higher.

\footnotetext{
${ }^{36}$ In Online Appendix Table E.29 we demonstrate from Census data that such a divergence also occurred in educational outcomes over the years 1990-2013.
} 


\section{Initial exposure and the evolution of finer job categories}

The literature on labor market polarization quite naturally focused attention on the loss of middle-paid jobs. The most prominent accounts of this loss have focused on the twin threats of routinizability and offshorability. In the empirics this focused attention, in turn, on loss of the most routinizable and offshorable (MRO) jobs, and especially whether locations' exposure to these MRO jobs is a good predictor of loss of these jobs. We replicate this inquiry and answer in the affirmative, confirming the prior work.

However, this narrowing of the question from the loss of middle-paid jobs broadly to just a subset of these jobs leaves open questions. Is exposure to MRO jobs a good predictor of losses of other middle-paid (OMP) jobs or of middle-paid jobs taken as a whole? We will find that high exposure to MRO jobs, to the contrary, is associated with modest loss of OMP jobs and of middle-paid jobs taken as a whole.

These facts lead us to re-examine these changes in middle-paid jobs through the lens of our model. In particular, our model emphasizes two margins of adjustment, as middle-paid jobs are substituted alternately by low- or high-paid jobs. And it emphasizes that the magnitudes of the middle-paid job losses, and the relative importance of each margin, will differ according to the size of the city. Under stated conditions, our theory predicts that the magnitude of loss of middle-paid jobs will be larger in large cities and that these cities will also see a relatively large loss of these jobs at the upper end of the middle-paid jobs, and vice versa for smaller cities. We examine these predictions of our model and find strong support in the French data.

\subsection{Exposure and the loss of the most routinizable and offshorable (MRO) jobs}

We investigate whether cities with a higher exposure to the most routinizable and offshorable jobs (our MRO group) see the largest decline in the share of these jobs. In the lowest panel of Table 3 we report both the 1994 and 2015 employment shares in the four CS 2-digit MRO occupations in six city groups. The employment share in these four MRO jobs are declining in city size both in 1994 and in $2015,{ }^{37}$ in line with the patterns for middle-paid occupations overall (Fact 2).

In the lowest panel of Table 3, the evolution of these shares over this period is relatively constant in percentage points: we see that the fall of shares in this category of middle-paid jobs is similar across metropolitan areas without any clear relationship with size - between 10.5 and 13.1 percentage points. Table 5, shows no statistically significant difference between large and small cities in the change in these MRO occupations. The same conclusion arises in rank-correlation tests (Online Appendix Table E.27).

However, these statements do not control for actual exposure to these specific jobs at the city

\footnotetext{
${ }^{37}$ We reconfirm this observation using rank correlations in the Online Appendix, Table E.28.
} 
level. It is clear from Figure 9 that large cities above $0.5 \mathrm{~m}$ people have lower initial exposures to the MRO occupations. ${ }^{38}$ Although there is considerable variation, Figure 9 confirms the observation of Autor and Dorn (2013) that the initial exposure to the most routine (and, in our context, also offshorable) jobs is strongly negatively correlated with their change as technological shocks occur. The observations for large cities lie in the lower envelope of observations. Thus conditional on initial exposure, the changes in the employment shares in these cities are larger than in other cities. Regression analysis in the Online Appendix Table E.22, top panel, confirms these points: initial exposure is negatively correlated with change in the MRO employment shares and the interaction of a dummy for large cities with exposure is robustly negatively different from zero. MRO jobs in large cities are destroyed at a higher rate than in small cities with the same initial exposure in reaction to the same automation or trade shocks.

In the end, consistent with Autor and Dorn (2013), we obtain:

Fact 8. The initial exposure to the most routinizable and offshorable jobs is a good predictor of the destruction of the most routinizable and offshorable jobs themselves.

\subsection{Exposure to MRO jobs and the broad loss of middle paid jobs}

We see that initial exposure to MRO jobs is strongly associated with subsequent loss of these jobs. But this raises the question of whether exposure to MRO jobs is also associated with the loss of other middle-paid (OMP) jobs, or indeed with middle-paid jobs taken as a whole.

We can look at the relation between initial exposure to MRO jobs and the subsequent change in OMP jobs in Figure 10. There is a strikingly strong negative relation between exposure to MRO jobs and subsequent loss of OMP jobs. The big losses of OMP jobs are in large cities, which have initially small exposure to MRO jobs.

We also know, though, from Fact 5 that large cities experienced a larger decline in middle-paid jobs overall (that include the MRO category). This leads us to suspect that the exposure to MRO jobs by itself may not be a good predictor of the overall change in middle-paid jobs.

Indeed, the population-weighted regression of changes in employment for the entire middlepaid category on initial exposure to the four MRO occupations (in the Online Appendix Table E.21, bottom panel) reveals a strong positive relationship (though the non-population weighted relationship is zero). There is clearly a larger destruction of middle-paid jobs in the largest cities conditioning on exposure, witnessed by the sign of the interaction of a dummy for large cities with MRO job exposure. For many small but highly-exposed cities, the drop in MRO jobs is larger than the decline in middle-paid jobs while the opposite is true for the largest cities. Thus, initial exposures to the MRO jobs are not a key driver of a broad measure of labor market polarization in local labor markets:

\footnotetext{
${ }^{38}$ The large cities with the highest initial exposure to MRO jobs are the Douai-Lens and Lille metropolitan areas, both located in the old industrial region in the North of France.
} 
Fact 9. The initial exposure to the most routinizable and offshorable (MRO) jobs is not a good predictor of the evolution of the entire class of middle-paid jobs across cities.

Even if automation and/or offshoring (Autor and Dorn, 2013; Goos et al., 2014) are driving labor market polarization, the extent to which these affect the broad category of middle-paid jobs does not depend only on a city's initial exposure to these most routinizable and offshorable jobs. These results are robust to considering a larger set of occupations for the most routinizable and offshorable jobs and also a longer time period (Online Appendix E.7). ${ }^{39}$

\subsection{Initial exposure and a broad measure of middle paid job loss}

We have seen that, as in Autor and Dorn (2013), initial exposure to MRO jobs is a good predictor of the loss of MRO jobs themselves, but is not a good predictor of loss for the broader class of middle-paid jobs. This raises the question of whether a measure of initial exposure to the broader measure of middle-paid jobs will itself be a good predictor of the broader loss of middle-paid jobs. This turns out not to be the case. Fact 2 states that the share of middle-paid jobs was initially lower in large cities. Fact 5 shows that large cities have nonetheless experienced a stronger decline in middle-paid jobs. Indeed, as reported in regressions in Table 6 we find no evidence that greater initial exposure leads to greater middle-paid job loss. Initial shares of middle-paid jobs either are negatively correlated with the magnitude of the decline in middle-paid jobs (in population weighted regressions) or there is no correlation between these quantities at all. Furthermore, conditioning on exposure, the destruction of middle-paid jobs was stronger in larger cities for all specifications. Hence:

Fact 10 (Initial exposure and middle-paid jobs). Initial exposure to middle paid jobs is not a good predictor of the destruction of middle-paid jobs.

This stands in contrast to Autor and Dorn (2013)'s idea that exposure is the key driver of labor market polarization in local labor markets. In comparison, a stronger decline in middle-paid jobs in larger cities conditional on exposure is consistent with our theory and, more precisely, with Corollary 3, which predicts that larger cities have a lower initial exposure to middle-paid jobs but experience a stronger decline in the share of these jobs.

\footnotetext{
${ }^{39}$ In the Online Appendix, Table E.26 we show the patterns for the 6 most offshorable jobs encompassing not only the four MRO occupations, but also categories such as transport and logistics personnel (CS 65) and mid-level professionals (CS 46). The shares of such jobs in total employment are monotonically decreasing with city size whether in 1994 or 2015. Percentage point fall in the employment shares of these occupations between 1994 and 2015 is higher in larger cities, thus confirming our results. Moreover, it can be seen in Figure E.11 that a higher initial exposure to offshorable jobs leads to their greater decrease in the studied period. This time, however, large cities are relatively more exposed to offshorable jobs in comparison to MRO occupations only as - in particular they have on average a higher share of the CS 46 category, mid-level professionals (cf. also Table E.26). In Table E.23 we demonstrate that the initial exposure to this wider set of occupations is also a good predictor of their employment share change. Again, conditional on exposure, offshorable jobs' employment shrinks by more in large cities in the studied period.
} 


\subsection{Skills, middle-paid jobs and labor market polarization across cities.}

The results so far pose puzzles about how to make sense of the spatial patterns. The origin of our concerns is about middle-paid job loss broadly. Exposure to the most routinizable and offshorable jobs, consistent with prior work, does explain loss of precisely those jobs. However we have also seen that neither exposure to MRO jobs nor to a broad measure of middle- paid jobs leads to a greater loss of our broad measure of middle-paid jobs. In contrast to prior work, our theory places emphasis both on heterogeneity of middle-paid jobs by skill and how that translates, given a common shock, into distinct experiences in large and small cities. We explore those dimensions of heterogeneity here to probe further how to match patterns of job loss and gain in large and small cities.

As noted above, the MRO jobs declined by roughly the same percentage points in cities of all sizes, while the remaining middle-paid jobs declined more sharply in larger cities. As we see in Table 3, in large cities the total loss of middle-paid jobs exceeds the number of jobs lost in the four MRO jobs (20 vs. 11 percentage points), while in smaller cities of between 0.05-0.1m inhabitants MRO jobs account for essentially all of the lost jobs. For Paris, the decline of the other middlepaid (OMP) occupations overall (9.6 percentage points) is very close to that of MRO jobs (10.5 percentage points) while in metropolitan areas with more than $0.75 \mathrm{~m}$ inhabitants the hours worked in OMP jobs decline by 5.2 percentage points.

Our Proposition 5 predicts that there will be different patterns of middle-paid job loss in large and small cities, namely that these will be relatively stronger among the most highly skilled middlepaid jobs in the large relative to the small city. One could map this into our data in more than one way, so we will consider two ways to divide the middle-paid jobs. First we note that MRO jobs are on average less skilled than OMP jobs, so that is our first division. More closely tied to our theoretical framework, we can also divide the middle-paid occupation by the median wage. These two divisions of the middle-paid jobs are illustrated in the two parts of Figure 11. As before we contrast cities of different sizes and the evolution of the high-paid and low-paid jobs for these are as before. The new information is in what type of middle-paid jobs are lost.

The first panel of Figure 11, dividing by MRO versus OMP jobs, is consistent with our approach, but more strongly tied to the traditional focus only on MRO jobs. This highlights that the existing literature's focus only on OMP jobs does a very good job of capturing middle-paid job loss in smalland middle-size cities, but ignores the strong differential OMP job loss in large cities.

The second panel of Figure 11, most closely tied to our theory, divides the middle-paid occupations according to the median wage. Here it is clear that there is a sharp difference between large and small cities. For large cities, there is an 11.7 percentage point rise in high-paid jobs, which is only slightly less than the 13.1 percentage point decline in the upper-tier middle-paid jobs. By contrast, in small cities, there is only a 3.9 percentage point growth of high-paid jobs, even as there is a 7.7 percentage point decline in these upper-tier middle-paid jobs. These patterns are consistent 
with the link our model provides between labor market polarization and the great divergence. ${ }^{40}$

Additional comparisons across large and small cities (Table 5 with additional statistics in Online Appendix Table E.20) further confirm these tendencies. ${ }^{41}$ The magnitude and reallocation effects, and the difference in the behavior of middle-paid jobs are clearly visible in Figures E.4 and E.5, where we superimpose the employment share changes in Paris and Lyon vs. those in cities with population between $0.05-0.1 \mathrm{~m}$.

In the end, we obtain the following fact:

Fact 11. The greater destruction of middle-paid jobs in larger cities compared with smaller ones is due to the destruction of more skilled and better paying middle-paid jobs in large cities.

Our conclusion is that an understanding of the variety of experience of cities of different sizes in the presence of an offshoring or routinizability shock needs to go beyond simple measures of exposure to the most offshorable or routinizable occupations. In particular, it is crucial to consider the heterogeneity of occupations within the middle-paid occupations. All cities lost jobs in roughly equal percentage points in the lower paid, most routinizable and offshorable middle-paid jobs. But, consistent with our model, the sharp differences across cities come in the upper tier of middle-paid jobs, where there are much sharper declines in larger cities.

\section{Conclusions}

Labor market polarization is a strong feature in recent decades of many advanced economies. The defining loss of middle-paid jobs along with the growth of both low- and high-paid jobs appears in the United States and many European countries. Over the same time period, some have expressed concern about the diverging fates of already-skilled, typically larger cities and less skilled, typically smaller cities. This second phenomenon is referred to as the great divergence. This paper seeks to understand labor market polarization and the great divergence within a common theoretical framework and then to use this framework to probe into important patterns in the data that otherwise might appear puzzling.

Our theory has simple elements that yield a rich pattern of predictions. Building on the prior literature on labor market polarization, we consider three intermediate tasks that can be thought of as low-, middle-, and high-paid jobs. There is another input which is a substitute for the middlepaid job and a complement to the low-and high-paid jobs. This input can be thought of either

\footnotetext{
${ }^{40}$ In Figure E.6, we provide further divisions of the middle-paid jobs depending on their wage. These patterns are also evident in rank correlations between city-level population and changes in occupational employment shares (Table E.27).

${ }^{41}$ Moreover, at the city level, Figures E.9 and E.10 show vividly that the difference across middle-paid jobs categories comes from the behavior of the more skilled (above the median wage in 1994) middle-paid occupations that combined decline more than middle-paid jobs below the median wage, and that this decline is particularly stronger in larger cities (that are also least exposed to MRO occupations; cf. Appendix Table E.22).
} 
as capital that allows routinization or an intermediate input that is offshored. To this standard setting for labor market polarization, we add elements of labor heterogeneity with individual-level comparative advantage, whereby individuals select into one or another of the three types of jobs; city-level absolute and comparative advantage across the jobs; and structure on how the comparative advantage varies across these cities. This setting provides conditions for a broad range of predictions that we can take to the data.

We examine these questions of labor market polarization and the great divergence using detailed data over the period 1994-2015 for a sample of 117 French cities. The data employed includes inter alia population, skills, employment by occupation, and measures of routinizability and offshorability of jobs. The data validate baseline predictions from the theory, including a log-supermodular distribution of skills and differential patterns of employment, whereby at baseline larger cities have less employment in middle-paid jobs and relatively more employment in high paid jobs.

Consistent with prior work, we find labor market polarization in the aggregate for France in the study period. We go beyond this to show that labor market polarization is very close to ubiquitous at the local level, with 115 of 117 cities sharing this feature. In spite of this, we also show that these patterns differ importantly in cities of different sizes. Large cities have a sharper loss of middle-paid jobs. Yet in the large cities these jobs are replaced two-to-one with high paid jobs, and the reverse pattern in small cities. All of these observations are consistent with our theoretical framework.

In the prior work on labor market polarization, the primary spatial concept of concern was exposure. The literature showed that the regions most exposed to middle-paid routinizable and offshorable jobs at baseline were also the regions that had the sharpest decline in these jobs in the periods of study. While very insightful, these studies also have limitations. First, these are only a subset of the lost middle-paid jobs, and so the empirics are unclear to what extent this exposure is also indicative of the loss of other middle-paid jobs or of the entire class of middle-paid jobs. This would require thinking about dimensions of heterogeneity within the class of middle-paid jobs that the prior frameworks are not designed to address, but which is central to what we do.

Our data confirms the prior result that cities with a large initial exposure to the most routinizable and offshorable jobs indeed have the sharpest contraction of these jobs in the study period. Importantly, though, we find that the loss of other middle-paid jobs and indeed of middle-paid jobs taken as a whole have the reverse pattern that might be expected from this. It is the large cities that have the greatest loss of the middle-paid jobs, even though the initial exposure to these jobs is smaller in large cities. Moreover, consistent with our framework, the primary difference between large and small cities occurs in the upper tail of middle-paid jobs, which decline sharply in large cities even as high skill jobs there expand greatly.

In sum, we find that the period of study identifies two Frances. In the France of large cities, there is a dramatic change, as there is a sharp contraction of middle-paid jobs, particularly at the top end of these. However in the France of large cities, these middle-paid jobs are largely 
replaced by high-paid jobs, with a more modest expansion of low-paid jobs. Still there is very sharp polarization within these cities. In the France of small cities, there is a strong, yet more moderated, loss of middle-paid jobs. Some high paid jobs are gained, but the lost middle-paid jobs are primarily replaced by low paid jobs. Polarization of jobs in the aggregate and within cities is accompanied by a great divergence between the Frances of large and small cities. 


\section{References}

Acemoglu, Daron, "Changes in Unemployment and Wage Inequality: An Alternative Theory and Some Evidence," American Economic Review, December 1999, 89 (5), 1259-1278.

- and David Autor, "Skills, tasks and technologies: Implications for employment and earnings," in "Handbook of labor economics," Vol. 4, Elsevier, 2011, pp. 1043-1171.

_ and _, "What Does Human Capital Do? A Review of Goldin and Katz's The Race between Education and Technology," Journal of Economic Literature, June 2012, 50 (2), 426-63.

_ and Pascual Restrepo, "Low-Skill and High-Skill Automation," Journal of Human Capital, 2018, 12 (2), 204-232.

_ and _ , "Robots and Jobs: Evidence from US Labor Markets," Journal of Political Economy, forthcoming.

Autor, David, "Work of the Past, Work of the Future," NBER Working Papers 25588, National Bureau of Economic Research February 2019.

Autor, David H. and David Dorn, "The Growth of Low-Skill Service Jobs and the Polarization of the US Labor Market," American Economic Review, 2013, 103 (5), 1553-1597.

Autor, David H, David Dorn, and Gordon H Hanson, "The China syndrome: Local labor market effects of import competition in the United States," American Economic Review, 2013, 103 (6), 2121-68.

_, Frank Levy, and Richard J Murnane, "The skill content of recent technological change: An empirical exploration," Quarterly Journal of Economics, 2003, 118 (4), 1279-1333.

Autor, David H., Lawrence F Katz, and Melissa S Kearney, "The polarization of the US labor market," American Economic Review, 2006, 96 (2), 189-194.

Behrens, Kristian, Gilles Duranton, and Frédéric Robert-Nicoud, "Productive cities: Sorting, selection, and agglomeration," Journal of Political Economy, 2014, 122 (3), 507-553.

Caliendo, Lorenzo, Ferdinando Monte, and Esteban Rossi-Hansberg, "The Anatomy of French Production Hierarchies," Journal of Political Economy, 2015, 123 (4), 809-852.

Cerina, F., E. Dienesch, A. Moro, and M. Rendall, "Spatial Polarization," Working Paper CRENoS 201909, Centre for North South Economic Research, University of Cagliari and Sassari, Sardinia 2019.

Cortes, Guido Matias, "Where Have the Middle-Wage Workers Gone? A Study of Polarization Using Panel Data," Journal of Labor Economics, 2016, 34 (1), 63-105. 
Costinot, Arnaud, "An Elementary Theory of Comparative Advantage," Econometrica, 2009, 77 (4), 1165-1192.

_ and Jonathan Vogel, "Matching and Inequality in the World Economy," Journal of Political Economy, August 2010, 118 (4), 747-786.

Davis, Donald R. and Jonathan I. Dingel, "A Spatial Knowledge Economy," American Economic Review, January 2019, 109 (1), 153-70.

_ and _ , "The comparative advantage of cities," Journal of International Economics, 2020, 123, 103291.

Diamond, Rebecca, "The Determinants and Welfare Implications of US Workers' Diverging Location Choices by Skill: 1980-2000," American Economic Review, March 2016, 106 (3), 479524.

Eckert, Fabian, "Growing Apart: Tradable Services and the Fragmentation of the U.S. Economy," 2019 Meeting Papers 307, Society for Economic Dynamics 2019.

Eeckhout, Jan, Roberto Pinheiro, and Kurt Schmidheiny, "Spatial Sorting," Journal of Political Economy, 2014, 122 (3), 554-620.

Ganong, Peter and Daniel Shoag, "Why has regional income convergence in the U.S. declined?," Journal of Urban Economics, 2017, 102 (C), 76-90.

Gaubert, Cecile, "Firm Sorting and Agglomeration," American Economic Review, November 2018, 108 (11), 3117-3153.

Giannone, Elisa, "Skill-Biased Technical Change and Regional Convergence," 2017 Meeting Papers 190, Society for Economic Dynamics 2017.

Gibbons, Robert, Lawrence F. Katz, Thomas Lemieux, and Daniel Parent, "Comparative Advantage, Learning, and Sectoral Wage Determination," Journal of Labor Economics, 2005, 23 (4), 681-724.

Goldin, Claudia Dale and Lawrence F Katz, The race between education and technology, Harvard University Press, 2009.

Goos, Maarten, Alan Manning, and Anna Salomons, "Job Polarization in Europe," American Economic Review, May 2009, 99 (2), 58-63.

_, _, and _, "Explaining Job Polarization: Routine-Biased Technological Change and Offshoring," American Economic Review, August 2014, 104 (8), 2509-2526. 
_ and _ , "Lousy and lovely jobs: The rising polarization of work in Britain," Review of Economics and Statistics, 2007, 89 (1), 118-133.

Harrigan, James, Ariell Reshef, and Farid Toubal, "The March of the Techies: Technology, Trade, and Job Polarization in France, 1994-2007," NBER Working Papers 22110, National Bureau of Economic Research March 2016.

_ , _, and _ , "Techies, Trade, and Skill-Biased Productivity," NBER Working Papers 25295, National Bureau of Economic Research November 2018.

Katz, Lawrence F and Kevin M Murphy, "Changes in relative wages, 1963-1987: supply and demand factors," Quarterly Journal of Economics, 1992, 107 (1), 35-78.

Moretti, Enrico, The New Geography of Jobs, Houghton Mifflin Harcourt, 2012.

Rosen, Sherwin, "The economics of superstars," American Economic Review, 1981, 71 (5), 845858. 


\section{A Figures and tables}

Table 1 - Sample statistics by 2 digit CS categories.

\begin{tabular}{|c|c|c|c|c|c|c|c|}
\hline \multirow[t]{2}{*}{$\mathrm{CS}$} & \multirow[t]{2}{*}{ Description } & \multicolumn{2}{|c|}{$\begin{array}{c}\text { Employment Share } \\
\text { percent }\end{array}$} & \multicolumn{2}{|c|}{$\begin{array}{l}\text { Average City Wage } \\
\text { (in } 2015 \text { euros) }\end{array}$} & \multicolumn{2}{|c|}{$\begin{array}{c}\text { Routine Offshorable } \\
\text { rankings }\end{array}$} \\
\hline & & 1994 & 2015 & 1994 & 2015 & & \\
\hline \multicolumn{8}{|c|}{ high-paid occupations } \\
\hline 23 & CEOs & 1.0 & 0.9 & 42.81 & 59.20 & 16 & 17 \\
\hline 37 & managers and professionals & 6.2 & 10.2 & 32.52 & 38.56 & 15 & 16 \\
\hline 38 & engineers & 5.1 & 9.0 & 30.36 & 33.69 & 17 & 10 \\
\hline 35 & creative professionals & 0.5 & 0.5 & 22.83 & 31.80 & 14 & 11 \\
\hline \multicolumn{8}{|c|}{ middle-paid occupations } \\
\hline 48 & supervisors and foremen & 4.1 & 2.7 & 18.03 & 21.86 & 3 & 3 \\
\hline 46 & mid-level professionals & 12.3 & 7.6 & 17.54 & 21.20 & 13 & 6 \\
\hline 47 & technicians & 5.7 & 6.3 & 17.15 & 20.60 & 11 & 7 \\
\hline 43 & mid-level health professionals & 0.8 & 1.5 & 15.05 & 18.05 & 10 & 13 \\
\hline 62 & skilled industrial workers & 14.1 & 9.3 & 13.52 & 17.99 & 4 & 2 \\
\hline 54 & office workers & 11.8 & 11.2 & 13.17 & 16.98 & 1 & 4 \\
\hline 65 & transport and logistics personnel & 2.9 & 3.0 & 11.96 & 16.00 & 5 & 5 \\
\hline 63 & skilled manual workers & 8.0 & 8.3 & 11.90 & 15.50 & 7 & 8 \\
\hline 64 & drivers & 5.0 & 5.5 & 11.50 & 14.46 & 18 & 18 \\
\hline 67 & unskilled industrial workers & 10.9 & 5.7 & 11.02 & 14.72 & 2 & 1 \\
\hline \multicolumn{8}{|c|}{ low-paid occupations } \\
\hline 53 & security workers & 0.7 & 1.4 & 10.60 & 14.60 & 9 & 12 \\
\hline 55 & sales-related occupations & 5.4 & 8.3 & 10.44 & 13.74 & 6 & 15 \\
\hline 56 & personal service workers & 2.2 & 4.8 & 9.97 & 12.63 & 12 & 14 \\
\hline 68 & unskilled manual workers & 3.3 & 3.8 & 9.11 & 13.28 & 8 & 9 \\
\hline
\end{tabular}

Notes: CS refers to the PCS 2-digit codes. In-sample values. Employment share for metropolitan mainland France (excluding Corsica). "Routine" ranking based on the RTI measure of Autor et al. (2003) while "Offshorable" on the OFF-GMS measure from Goos et al. (2014), both mapped into PCS 2-digit employment categories from the ISCO classification used by Goos et al. (2014). Occupations with employment shares above 2.5\% in 1994 in bold. We borrow the translation of 2-digit CS categories from Harrigan et al. (2016).

This Table gives the basic statistics by 2-digit occupational categories: the aggregate employment shares and city-level wages in 1994 and 2015 , and the routiness (RTI) and offshorability rankings.

There is a considerable gap between the average wages of cadres (high-paid jobs) and other workers in 1994 and 2015, with a less pronounced difference between middle and low-paid jobs. Hence we borrow the classification of middle and low-paid occupations from Goos et al. (2014). We form other groupings of middle-paid occupations used throughout the paper based on data shown in this table. We label CS 48, 54, 62 and 67 as MRO jobs as these are among both the 4 most routinizable and offshorable occupations. Consequently, other middle-paid jobs are labelled as OMP. Middle-paid jobs above the median average wage in 1994 are CS 43, 46, 47, 48 and 62. "Intermediate professions", that belong to the middle-paid jobs with wages above the median average wage, are those with the first CS digit "4" while employees and blue collar workers, respectively, with the first digit "5" or "6".

Rankings of routineness and offshorability confirm that it is typically the middle-paid jobs that are most exposed to automation and offshoring shocks. We can document here labor market polarization: Largest changes in employment shares over the period 1994-2015 are observed for precisely for the most exposed categories such as skilled and unskilled industrial workers (CS 62 and 67), supervisors and foremen (CS 48), mid-level professionals (CS 46) and to lesser extent office workers (CS 54). Employment shares increase most for some high-paid occupations (managers and professionals - CS 37; engineers - CS 38) or low-paid ones. 


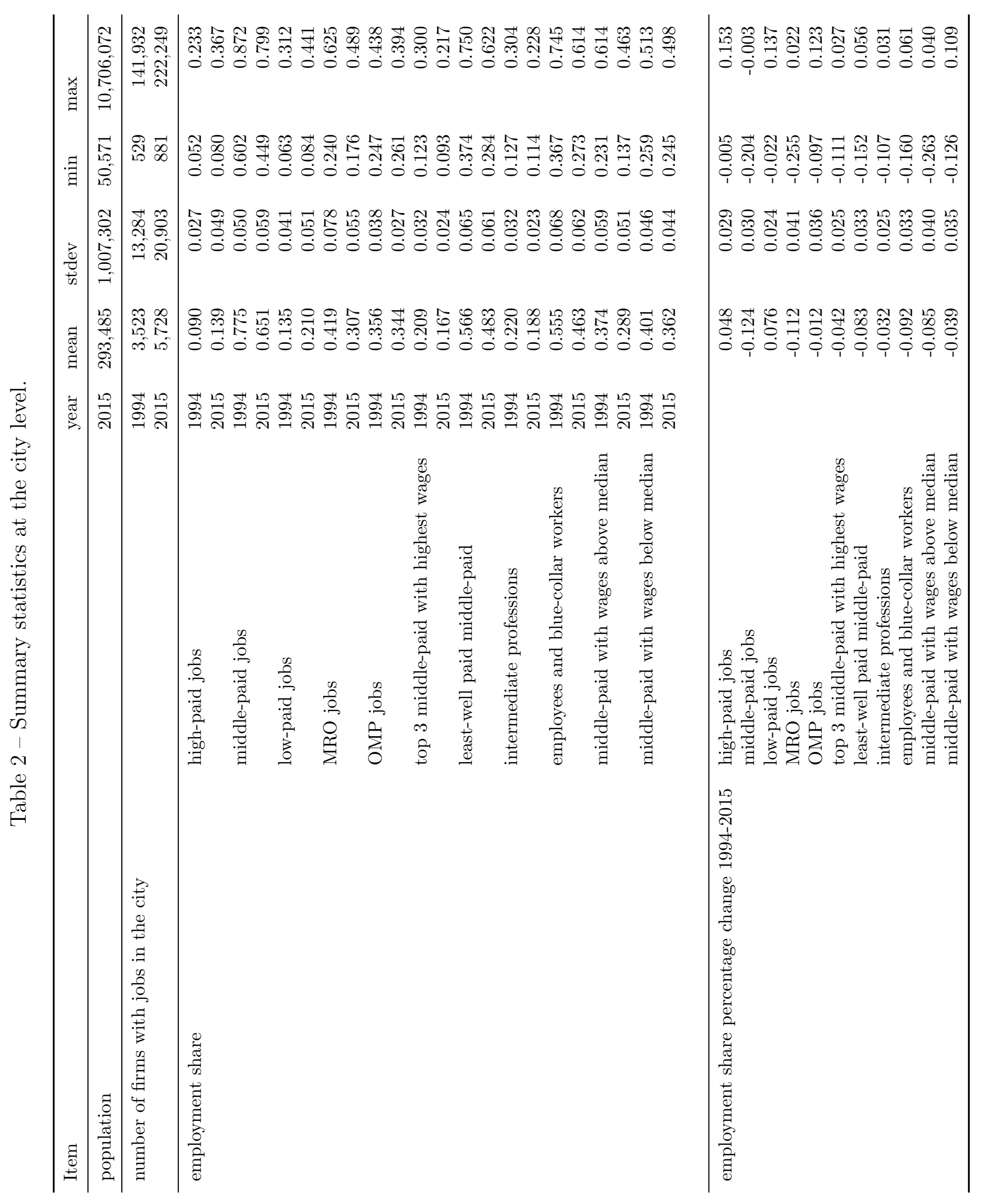


Table 3 - Share of high-, middle-, low-paid and MRO occupations in hours worked per metropolitan area size in 1994 and 2015.

\begin{tabular}{|c|c|c|c|c|c|c|c|}
\hline \multicolumn{8}{|l|}{ High-paid } \\
\hline Agglo.size & Paris & $>.75 \mathrm{~m}$ & $.5-.75 \mathrm{~m}$ & $.2-.5 \mathrm{~m}$ & $.1-.2 \mathrm{~m}$ & $.05-.1 \mathrm{~m}$ & All cities \\
\hline 1994 & 0.23 & 0.14 & 0.12 & 0.10 & 0.09 & 0.08 & 0.16 \\
\hline 2015 & 0.37 & 0.25 & 0.21 & 0.16 & 0.14 & 0.12 & 0.25 \\
\hline change & 0.13 & 0.11 & 0.09 & 0.06 & 0.05 & 0.04 & 0.10 \\
\hline growth in $\%$ & 57 & 77 & 71 & 63 & 61 & 49 & 62 \\
\hline \multicolumn{8}{|l|}{ Middle-paid } \\
\hline Agglo.size & Paris & $>.75 \mathrm{~m}$ & $.5-.75 \mathrm{~m}$ & $.2-.5 \mathrm{~m}$ & $.1-.2 \mathrm{~m}$ & $.05-.1 \mathrm{~m}$ & All cities \\
\hline 1994 & 0.65 & 0.74 & 0.75 & 0.77 & 0.79 & 0.79 & 0.72 \\
\hline 2015 & 0.45 & 0.57 & 0.61 & 0.64 & 0.66 & 0.67 & 0.56 \\
\hline change & -0.20 & -0.17 & -0.15 & -0.13 & -0.13 & -0.12 & -0.17 \\
\hline growth in $\%$ & -31 & -23 & -19 & -17 & -17 & -15 & -23 \\
\hline \multicolumn{8}{|l|}{ Low-paid } \\
\hline Agglo.size & Paris & $>.75 \mathrm{~m}$ & $.5-.75 \mathrm{~m}$ & $.2-.5 \mathrm{~m}$ & $.1-.2 \mathrm{~m}$ & $.05-.1 \mathrm{~m}$ & All cities \\
\hline 1994 & 0.12 & 0.12 & 0.12 & 0.13 & 0.12 & 0.13 & 0.12 \\
\hline 2015 & 0.18 & 0.18 & 0.18 & 0.20 & 0.20 & 0.21 & 0.19 \\
\hline change & 0.07 & 0.06 & 0.06 & 0.07 & 0.08 & 0.08 & 0.07 \\
\hline growth in $\%$ & 59 & 48 & 48 & 55 & 68 & 64 & 57 \\
\hline \multicolumn{8}{|l|}{$\overline{\mathrm{MMRO}}$} \\
\hline Agglo.size & Paris & $>.75 \mathrm{~m}$ & $.5-.75 \mathrm{~m}$ & $.2-.5 \mathrm{~m}$ & $.1-.2 \mathrm{~m}$ & $.05-.1 \mathrm{~m}$ & All cities \\
\hline 1994 & 0.29 & 0.36 & 0.39 & 0.41 & 0.45 & 0.45 & 0.36 \\
\hline 2015 & 0.19 & 0.25 & 0.27 & 0.29 & 0.31 & 0.32 & 0.25 \\
\hline change & -0.11 & -0.11 & -0.12 & -0.12 & -0.13 & -0.12 & -0.12 \\
\hline growth in \% & -36 & -32 & -31 & -29 & -29 & -27 & -32 \\
\hline
\end{tabular}

This Table shows the means of shares of hours in total employment of different occupational groups in 1994 and 2015 for all 117 cities in our sample allocated in 6 bins according to city size (with Paris being a separate category), showing the percentage point changes and growth rates between 1994-2015. One observation per bin of the hours totals.

The share of high- (middle-) paid jobs in total employment is increasing (decreasing) with city size whether in 1994 or 2015 . It is constant for low-paid jobs in 1994 while weakly monotonically decreasing in city size as of 2015. Percentage point destruction of middle-paid jobs (also in terms of growth) is positively related with city size despite their lower initial share in employment for larger cities. Increases in high-paid jobs in percentage points are highest in largest cities, while there is no strong pattern for low-paid jobs. This provides evidence both for the magnitude and the reallocation effects in local labor markets.

The share of MRO jobs (CS 48, 54, 62 and 67) in total employment is decreasing with city size whether in 1994 or 2015. Percentage point destruction of these MRO jobs is similar across city sizes despite their lower initial share in employment for larger cities. 
Table 4 - Comparison of means of employment shares of different occupations, cities $>0.5 \mathrm{~m}$ vs. $0.05-0.1 \mathrm{~m}$.

\begin{tabular}{|c|c|c|c|c|c|c|c|}
\hline Item & high-paid & $\begin{array}{l}\text { middle- } \\
\text { paid }\end{array}$ & low-paid & $\mathrm{MRO}$ & $\mathrm{OMP}$ & $\begin{array}{l}\text { middle- } \\
\text { paid } \\
\text { above } \\
\text { median }\end{array}$ & $\begin{array}{l}\text { middle- } \\
\text { paid } \\
\text { below } \\
\text { median }\end{array}$ \\
\hline \multicolumn{8}{|l|}{1994} \\
\hline mean, cities $>0.5 \mathrm{~m}$ & 0.188 & 0.690 & 0.123 & 0.327 & 0.363 & 0.363 & 0.327 \\
\hline mean, cities $0.05-0.1 \mathrm{~m}$ & 0.081 & 0.780 & 0.140 & 0.426 & 0.354 & 0.360 & 0.420 \\
\hline difference & $0.107^{* * *}$ & $-0.09 * * *$ & $-0.017^{*}$ & $-0.10^{* * *}$ & 0.009 & 0.003 & $-0.094^{* * *}$ \\
\hline \multicolumn{8}{|l|}{2015} \\
\hline mean, cities $>0.5 \mathrm{~m}$ & 0.303 & 0.509 & 0.188 & 0.219 & 0.290 & 0.233 & 0.276 \\
\hline mean, cities $0.05-0.1 \mathrm{~m}$ & 0.117 & 0.664 & 0.219 & 0.315 & 0.348 & 0.287 & 0.377 \\
\hline difference & $0.186^{* * *}$ & $-0.155^{* * *}$ & $-0.031^{* * *}$ & $-0.096^{* * *}$ & $-0.058 * * *$ & $-0.054 * * *$ & $-0.101^{* * *}$ \\
\hline
\end{tabular}

Notes: 1990 population weighted, robust standard errors. $\mathrm{N}=73 ; 11$ cities $>0.5 \mathrm{~m}$ and 62 cities between $0.05-0.1 \mathrm{~m}$ inhabitants as of 2015. ***,**, and * denote statistical significance at the $1 \%, 5 \%$, and $10 \%$ levels for the tests of equality of means between the groups of small and large cities.

The Table shows the means of hours shares in total employment of different occupational groups for cities with $>0.5 \mathrm{~m}$ (large cities) and $0.05 \mathrm{~m}-0.1 \mathrm{~m}$ (small cities) inhabitants, and the comparison between the two types of cities. The reported difference in the means is a coefficient in the regression of shares on a large city dummy. Values are population weighted at the city level. The average share of high-paid jobs is higher while those of middle- or low-paid ones lower in larger cities both in 1994 and 2015 , with the differences being significant at least at a $10 \%$ level. The discrepancies appear to grow with time (cf. Table 5 for tests). The difference in middle-paid jobs patterns across cities in 1994 and also in 2015 comes from the shares of MRO or middle-paid job categories with wages below the median average wage that are less prevalent in large cities. There is no statistically significant difference between the average shares of OMP or middle-paid jobs with wages above the median average wage between the large and small cities 1994 . However, such a difference appears in 2015, and large cities have on average fewer middle-paid jobs in all considered categories. 
Table 5 - Comparison of means of changes in employment shares of different occupations at the city level, cities $>0.5 \mathrm{~m}$ vs. $0.05-0.1 \mathrm{~m}$.

\begin{tabular}{|c|c|c|c|c|c|c|c|}
\hline Item & high-paid & $\begin{array}{l}\text { middle- } \\
\text { paid }\end{array}$ & low-paid & $\mathrm{MRO}$ & $\mathrm{OMP}$ & $\begin{array}{l}\text { middle- } \\
\text { paid } \\
\text { above } \\
\text { median }\end{array}$ & $\begin{array}{l}\text { middle- } \\
\text { paid } \\
\text { below } \\
\text { median }\end{array}$ \\
\hline \multicolumn{8}{|l|}{ Changes } \\
\hline $\begin{array}{l}\text { mean change, cities } \\
>0.5 \mathrm{~m}\end{array}$ & 0.116 & -0.181 & 0.065 & -0.108 & -0.073 & -0.130 & -0.051 \\
\hline $\begin{array}{l}\text { mean change, cities } \\
0.05-0.1 \mathrm{~m}\end{array}$ & 0.037 & -0.116 & 0.080 & -0.111 & -0.006 & -0.073 & -0.044 \\
\hline difference & $0.079^{* * *}$ & $-0.065^{* * *}$ & $-0.015^{* * *}$ & 0.003 & $-0.068^{* * *}$ & $-0.057^{* * *}$ & -0.008 \\
\hline \multicolumn{8}{|l|}{ Growth in percent } \\
\hline $\begin{array}{l}\text { mean growth, cities } \\
>0.5 \mathrm{~m}\end{array}$ & 63.0 & -26.5 & 54.4 & -33.1 & -20.1 & -36.0 & -16.0 \\
\hline $\begin{array}{l}\text { mean growth, cities } \\
0.05-0.1 \mathrm{~m}\end{array}$ & 45.7 & -14.9 & 62.2 & -25.2 & -0.6 & -19.9 & -10.2 \\
\hline difference in growth & $17.2^{* * *}$ & $-11.6^{* * *}$ & -7.8 & $-7.9^{* * *}$ & $-19.5^{* * *}$ & $-16.1^{* * *}$ & $-5.8^{* * *}$ \\
\hline
\end{tabular}

Notes: 1990 population weighted, robust standard errors. $\mathrm{N}=73 ; 11$ cities $>0.5 \mathrm{~m}$ and 62 cities between $0.05-0.1 \mathrm{~m}$ inhabitants as of 2015. ***,**, and $*$ denote statistical significance at the $1 \%, 5 \%$, and $10 \%$ levels for the tests of equality of means between the groups of small and large cities. Differences remain significant at least at the $1 \%$ level without weighting or weighted by city population as of 2015 except for the difference in growth middle-paid below-median jobs for unweighted comparison. Individual mean changes or growth rates are significantly different from zero at the $1 \%$ level.

This Table shows the comparison of hours shares changes in total employment over the period 1994-2015 for different occupations for 11 largest cities $>0.5 \mathrm{~m}$ and 62 smallest cities between $0.05-0.1 \mathrm{~m}$ inhabitants. The reported differences are coefficients in regressions of changes or growth of shares on a large city dummy. Values are population weighted at the city level.

This provides evidence that city sizes matter for the diverging patterns of labor market polarization, both in terms of the magnitude and reallocation effects. There is a stronger destruction of middle-paid jobs in large cities in comparison to smallest ones (18.1 pp vs. $11.6 \mathrm{pp})$. In large cities, there are on average twice as many high-paid jobs as low-paid created (11.6 pp vs. 6.5 pp change). In smallest cities, however, the pattern is reversed: twice as many low-paid jobs are created (8 pp vs. 3.7 pp change for high-paid).

The differential pattern in the magnitude of the destruction of middle-paid jobs can be attributed to the stronger destruction of OMP and/or top paid middle-paid jobs (with average wages in 1994 above the median).

Intermediate patterns can be observed for cities between 0.1-0.5m inhabitants (not shown). 


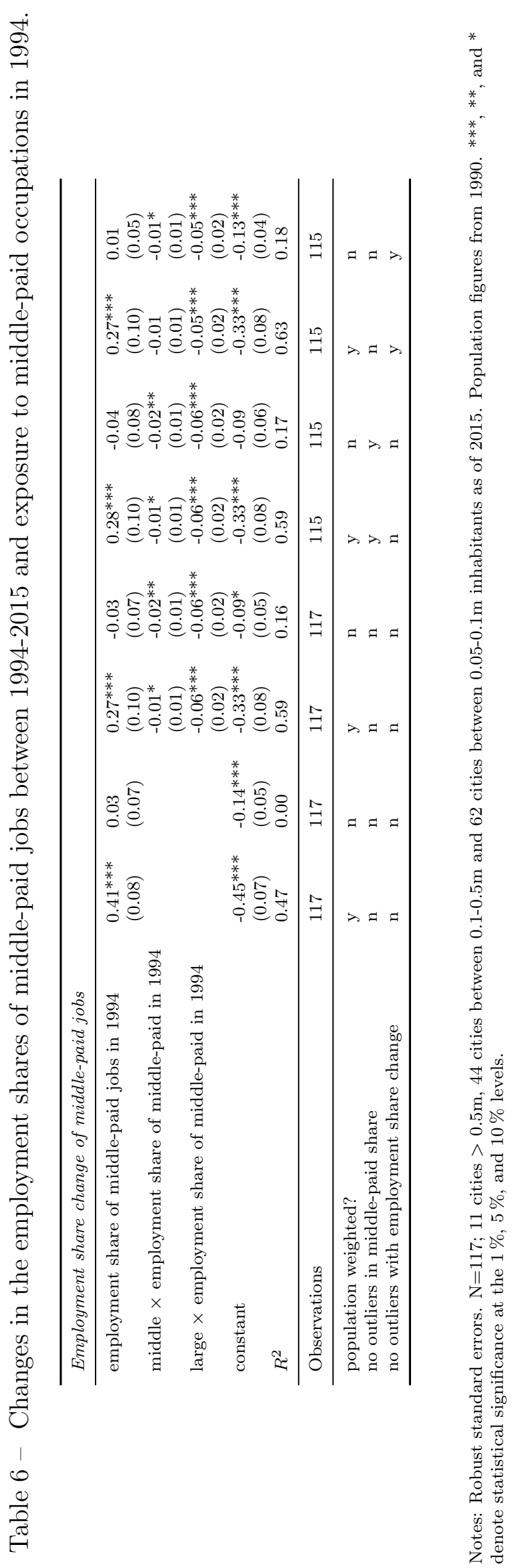

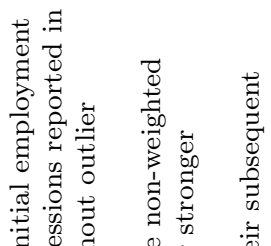

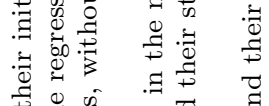

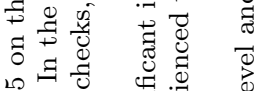

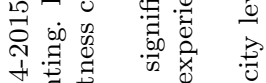

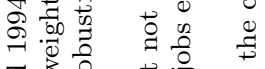

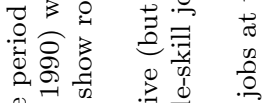

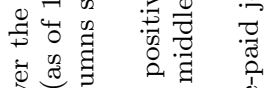

के 형

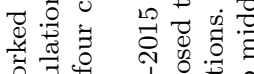

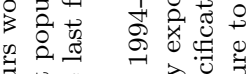

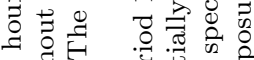

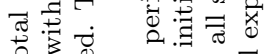

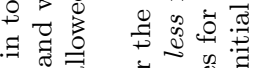

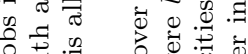
可 要

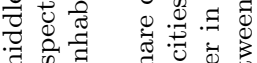

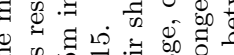

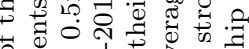
论

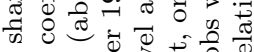

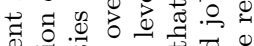

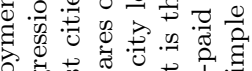
을 政

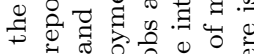

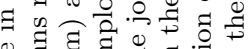
o 중 00

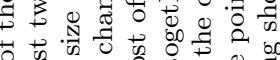

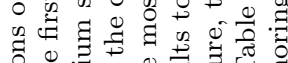

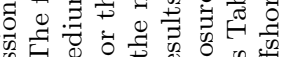

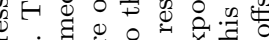

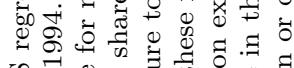

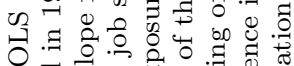

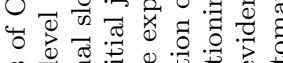

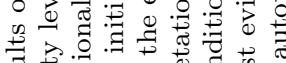

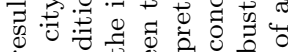

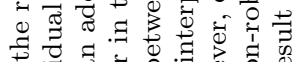

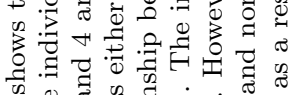
0 \%

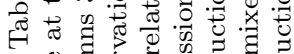

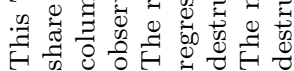




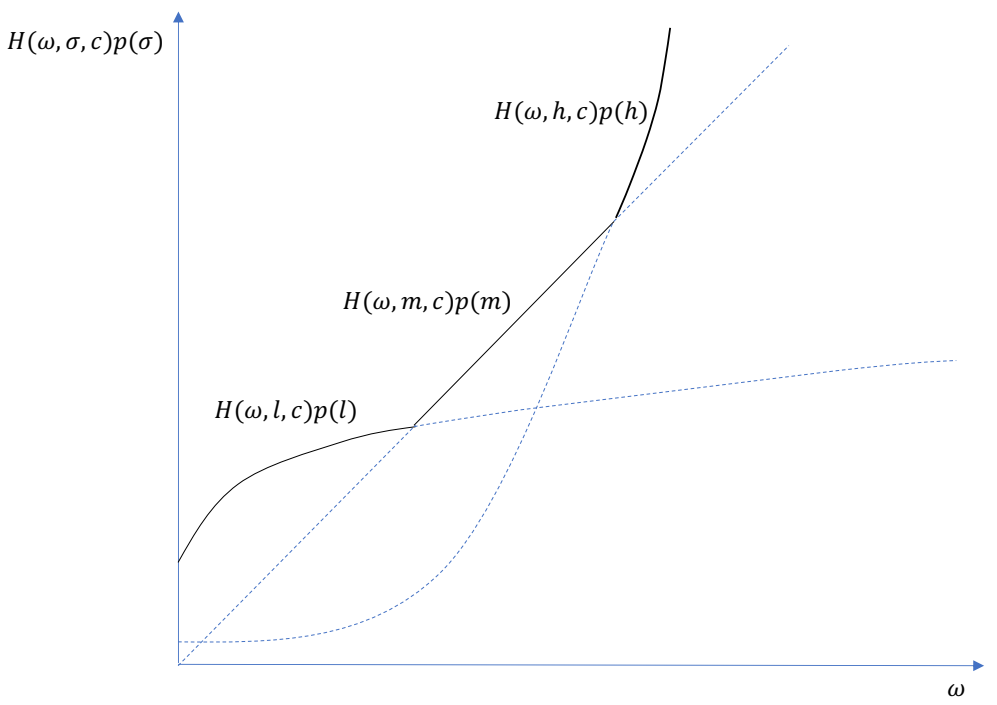

Figure 1 - Value marginal products in the different sectors.

This figure depicts the value marginal products as a function of the skill $\omega$ for the three sectors $\sigma \in\{h, m, l\}$. The value marginal productivity is the productivity function $H(\omega, \sigma, c)$ weighted by the price of the sector's output $(p(\sigma), \sigma \in\{h, m, l\})$. The plain black line is the upper envelope of these value marginal products.

$\omega$

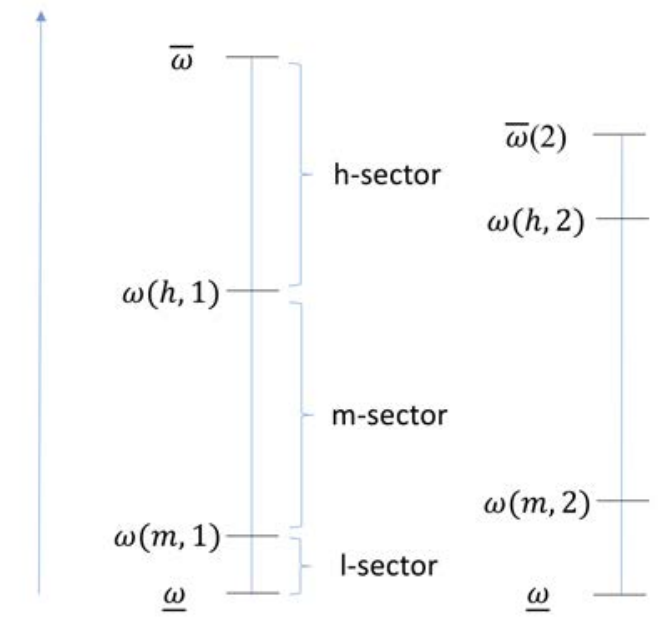

City 1

City 2

Figure 2 - Skills, sectors and cities in equilibrium.

This figure depicts the equilibrium skill range and sectoral choice for individuals as a function of their skill in the large (city 1) and the small city when all sectors are present in both cities. All skill types are present in city 1 . However, the small city lacks the most skillful agents with $\omega \in[\omega(2), \bar{\omega}]$ who choose all to reside in city 1 . In both cities, more able agents choose higher-paid sectors. Because of the assumptions about the absolute and comparative advantage of city 1 in higher-skill sectors, the skill thresholds for agents to choose the high- or middle-paid sectors are lower in the larger city: $\omega(h, 1)<\omega(h, 2)$ and $\omega(m, 1)<\omega(m, 2)$. If the absolute advantage of the high-skill sector in city 1 is large enough, the share of workers in the high- (middle-) skill sector will be higher (lower) in the larger city. 


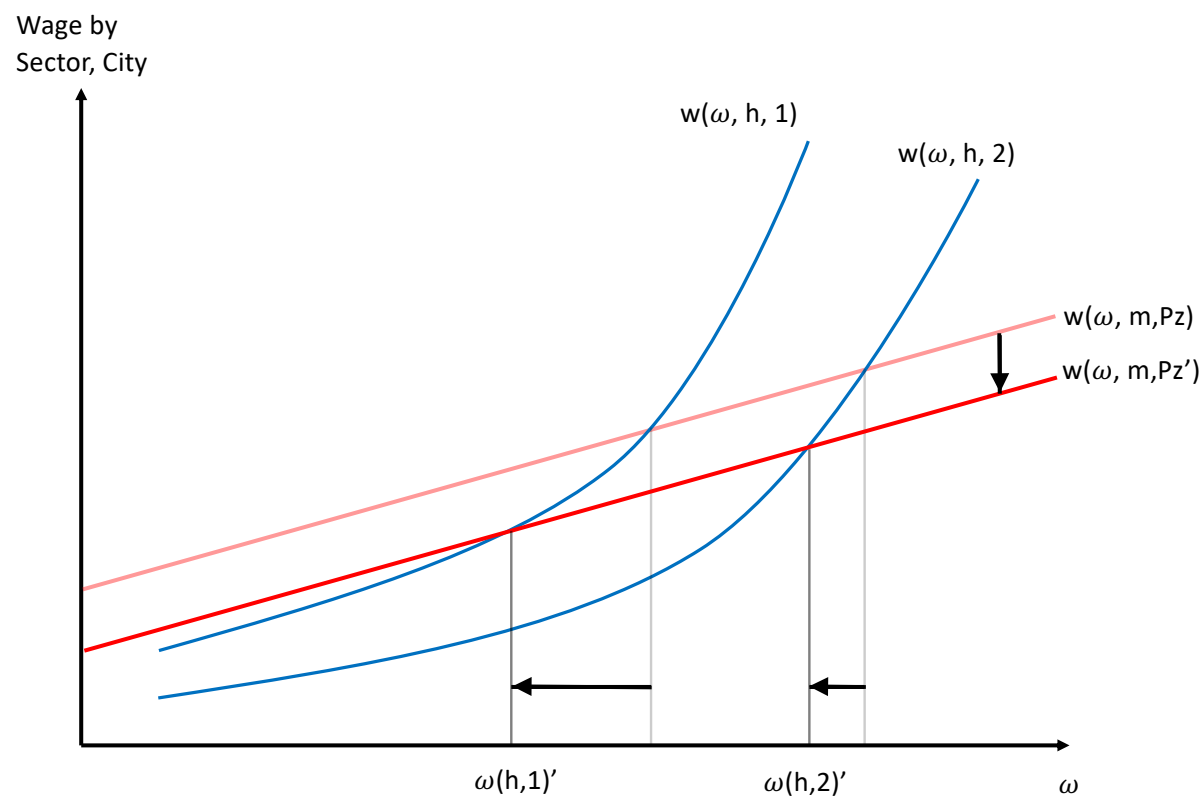

Figure 3 - Effect of a decline of the price of the capital/offshoring good on sector decisions - special case of equal productivities of cities in the m sector

This graph plots the curves for the wages in sector $m$ - in red - and sector $h$ - in blue - as a function of skill $\omega$ for both city 1 and city 2 and for two levels of prices for the capital/offshoring good $\left(P_{z}>P_{z^{\prime}}\right)$. Because of the increasing convexity of the wage when shifting from the $\mathrm{m}$ to the $\mathrm{h}$ sector, a decline in $P_{z}$ leads to a stronger decline in the threshold $\omega(h, 1)$ than in $\omega(h, 2)$.

$\omega$

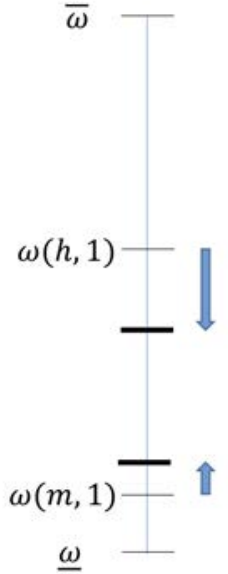

City 1

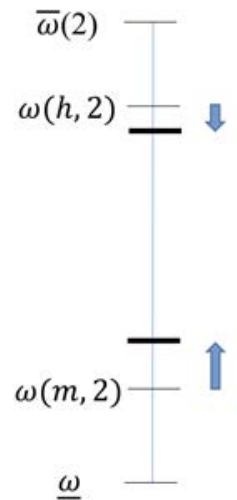

City 2

Figure 4 - The effects of a decline in the price of capital/offshored goods.

This figure shows the change in the equilibrium sectoral choices of agents as a result of the decline of the price of the capital/offshorable good $p_{z}$. Since the wages obtained by agents active in the middle-skill sector decline, agents with the highest opportunity costs working in this sector prior to the shock switch to high- and low-skill sectors in both cities. Given the technological assumptions, the decline (increase) in the skill threshold for agents to choose employment in the high- (low-) skill sector is larger (smaller) in city 1. As a result, there is a higher decrease in the middle-sector employment (despite a lower pre-shock share of employment in this sector as compared to city 2) and a higher (lower) increase in high- (low-) skill employment in the larger city 1. 
Figure 5 - Population elasticities by diploma (5 categories) in the 1999 Census data.

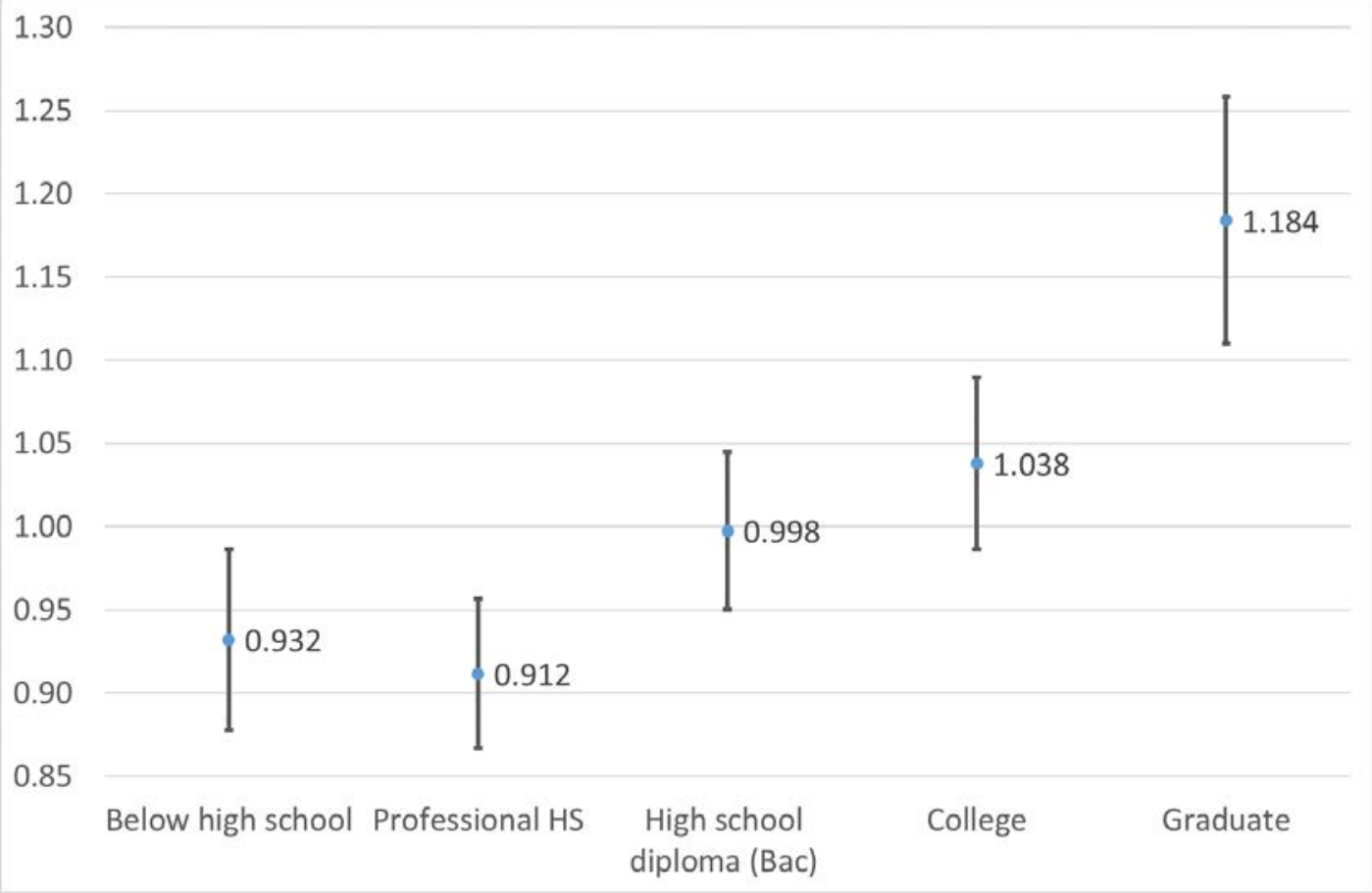

Notes: This sample contains 112 cities with $>0.05 \mathrm{~m}$ inhabitants defined by INSEE as of 1999 with population figures as of 1999 . Data on diplomas and residency is from the 1999 Census. Exclusions in terms of 2-digit CS and age as for the main DADS data used in the paper. $95 \%$ confidence intervals shown.

This Figure shows coefficients from regressions of the logarithm of the number of workers by five educational categories on the logarithm of city size. We observe log-supermodularity of skill distribution in city size as in Davis and Dingel (2020). The population elasticity for workers with graduate education (Master degrees and beyond) is 1.184 (significantly different from one at the $1 \%$ level) while for those with college (undergraduate) is 1.038. This means that larger cities have on average relatively more educated workers. At the same time, the least skilled (those with no diploma/a diploma below the general high school one or vocational - professional high school diplomas) are more likely to reside in smaller cities: the population elasticity estimates are significantly below one. The patterns do not qualitatively differ depending on whether we consider only the French-born fraction of the population. Further details are provided in Online Table E.6. 
Figure 6 - Labor market polarization in France 1994-2015.

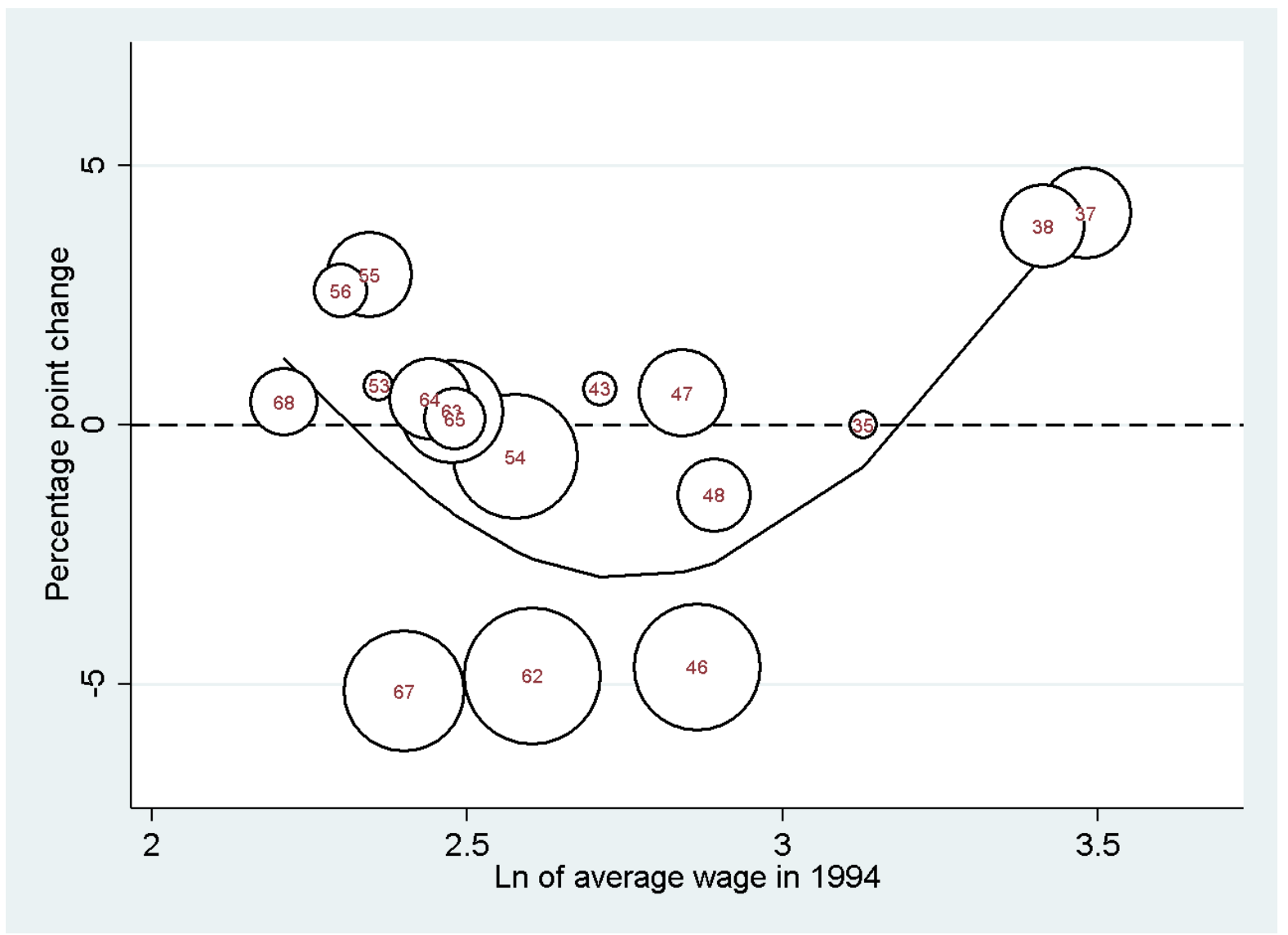

The figure shows the percentage point change in employment 1994-2015 of the considered 2-digit CS occupation categories plotted against their 1994 average wage in cities with $>0.05 \mathrm{~m}$ inhabitants as of 2015. Circle sizes correspond to employment shares in 1994 . The line shows a cubic relationship between the average wage and the percentage point change. The CS category "23" - CEOs excluded.

This figure documents labor market polarization that occurred between 1994-2015 in mainland France. One can observe an increase in the employment share of managers and professionals (CS 37) and engineers (CS 38) by approximately 4 pp each. At the other end of the income distribution, low-paid occupation's shares in employment increase as well. For middle-paid occupations, there exist occupation categories whose shares fell strongly (approximately 5pp) over the period: skilled (CS 62) and unskilled industrial workers (CS 67), and associate professionals (CS 46) or mildly: office workers (CS 54) or supervisors and foremen (CS 48). Many other middle-paid jobs show low or no employment share gains. The fitted cubic curve weighted by 1994 employment shares shows a similar U-relationship between average wages and percentage point changes in employment shares as in Autor and Dorn (2013). 
Figure 7 - Labor market polarization within cities and the great divergence.

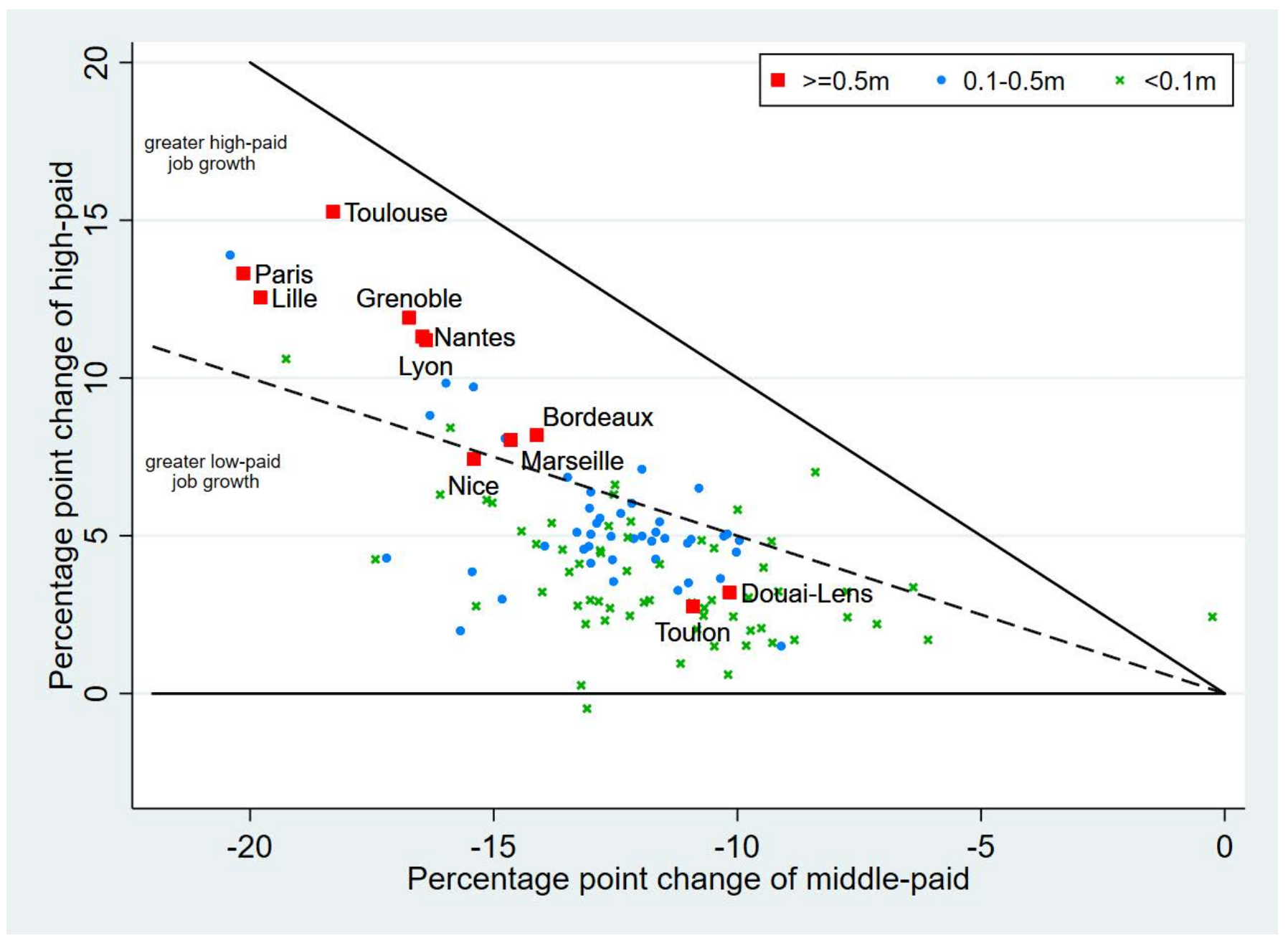

This figure shows percentage point changes in employment shares of middle-paid against high-paid jobs for individual cities for the period 1994-2015. Each red square, blue dot or green check symbolizes, respectively, a large (above $>0.5 \mathrm{~m}$ inhabitants), medium-sized $(0.1-0.5 \mathrm{~m})$ or small $(0.05-0.1 \mathrm{~m})$ city. Names of cities with more than $0.5 \mathrm{~m}$ inhabitants are shown. $\mathrm{N}=117 ; 11$ cities $>0.5 \mathrm{~m}, 44$ cities between $0.1-0.5 \mathrm{~m}$ and 62 cities between $0.05-0.1 \mathrm{~m}$ inhabitants in 2015 .

All 117 largest cities in France experienced a decline in employment of middle-paid jobs over the period 1994-2015. One small city (Saint Cyprien), pictured below the horizontal zero axis had a decline in high-paid jobs over this period while another (Salon de Provence; rightmost, above the -1 slope line) experienced a fall in the employment share of low-paid jobs. Apart from those two cases, labor market polarization occurred at 115 cities out of 117 studied, and in particular in all cities above ca. 60,000 inhabitants. Cities depicted above the line with $\left(-\frac{1}{2}\right)$ slope witnessed a stronger increase in the share of high-paid occupations. Most (8) large cities above $0.5 \mathrm{~m}$ inhabitants were in this category while three (Nice, Toulon and Douai-Lens) experienced a stronger growth of low-paid occupations instead. It is clear that a great majority of middle-sized and small cities experienced a stronger growth of low-paid than high-paid jobs. 
Figure 8 - The great divergence and labor market polarization across three different city size groups, 1994-2015: 3 employment groups.

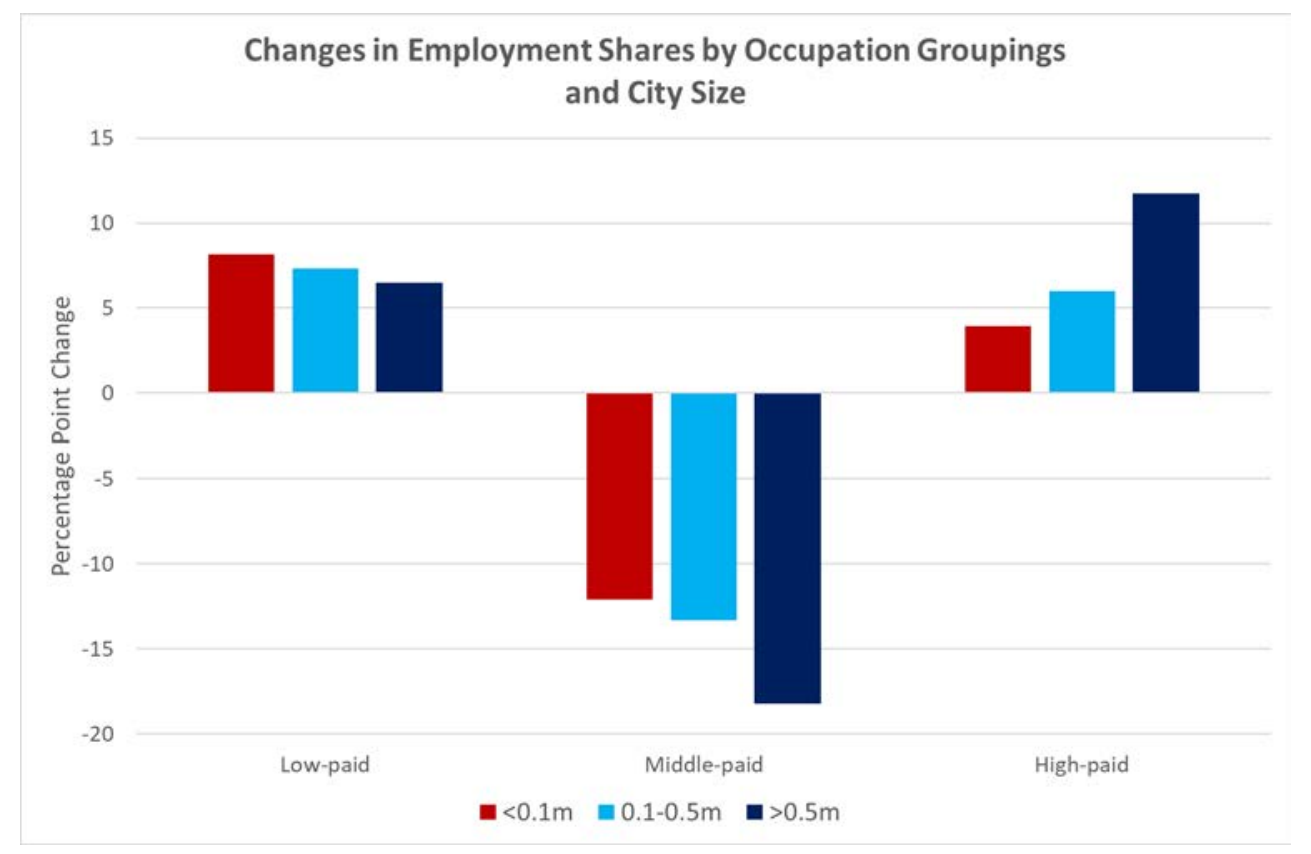

This figure shows percentage point changes in employment shares of high-, middle- and low-paid jobs with hours worked summed by the 3 job types and 3 city sizes: large (above $>0.5 \mathrm{~m}$ inhabitants), medium-sized $(0.1-0.5 \mathrm{~m})$ and small $(0.05-0.1 \mathrm{~m})$ in the period $1994-2015$. Destruction of middle-paid jobs was the strongest in largest cities (18.2 pp) and weakest in smallest cities (12.1 pp), confirming the magnification effect. At the same time, the creation of high-paid jobs was strongest in largest agglomerations (11.7 pp) and weakest in smallest cities $(3.9 \mathrm{pp})$. On the other hand, the strongest creation of low-paid jobs occurred in smallest cities (8.1 pp) while it was weakest in the cities above $>0.5 \mathrm{~m}(6.5 \mathrm{pp})$. The reallocation effect is clearly visible: nearly twice as many high-paid jobs as low-paid ones were created in largest cities, while the reverse was true in the smallest agglomerations. 
Figure 9 - Exposure to MRO jobs and change in the employment shares of MRO jobs in cities, 1994-2015.

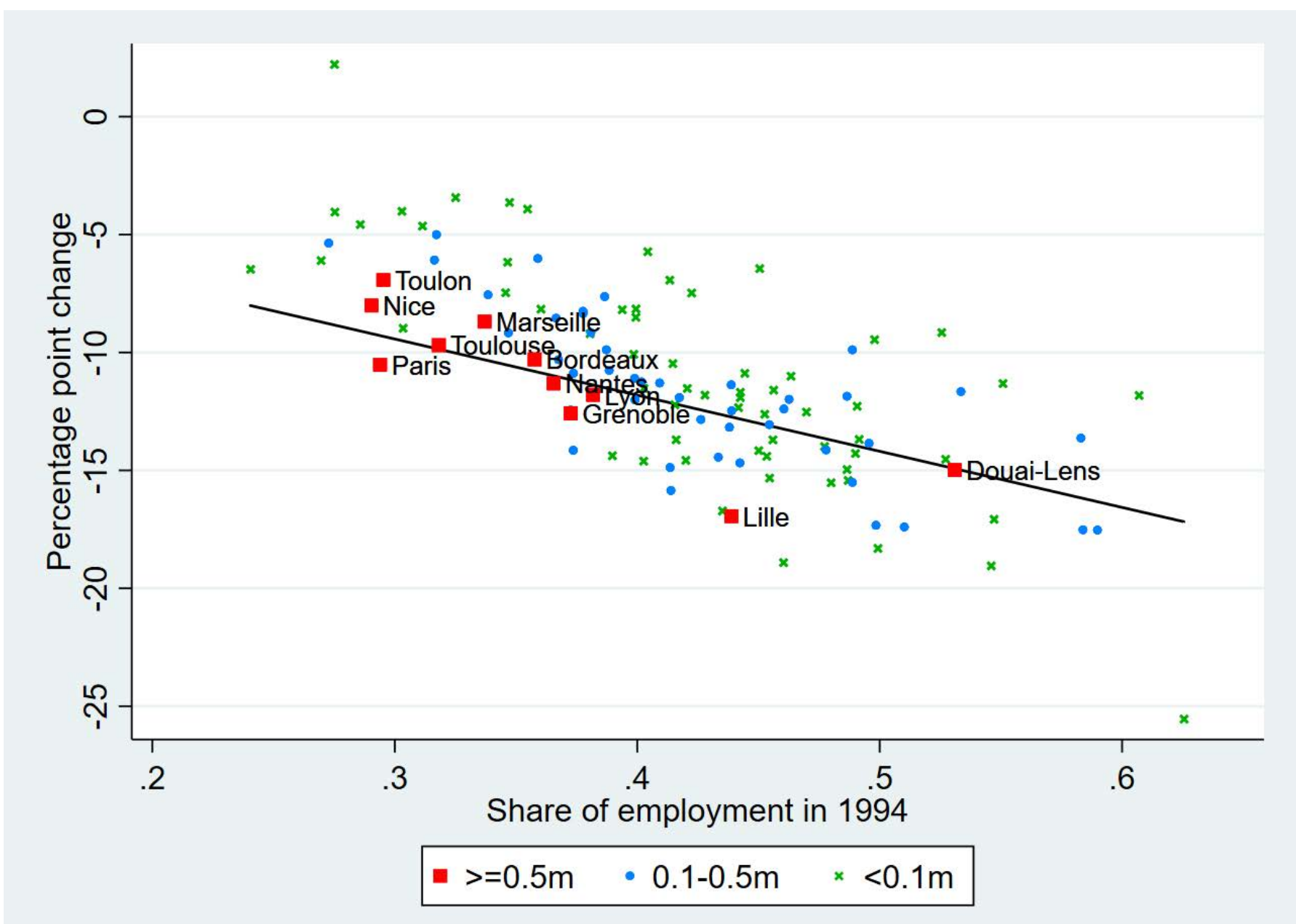

The figure shows the percentage point change in employment shares of MRO jobs (CS 48, 54, 62 and 67) between 1994-2015 plotted against their share in employment in 1994 at the city level. Each red square, blue dot or green check symbolizes, respectively, a large (above $>0.5 \mathrm{~m}$ inhabitants), medium-sized $(0.1-0.5 \mathrm{~m})$ or small $(0.05-0.1 \mathrm{~m})$ city. The line shows a linear, population-weighted (by 1990 population) fit of the relationship between employment changes and the initial exposure to MRO jobs. Names of cities with more than $0.5 \mathrm{~m}$ inhabitants are shown. $\mathrm{N}=117 ; 11$ cities $>0.5 \mathrm{~m}, 44$ cities between $0.1-0.5 \mathrm{~m}$ and 62 cities between $0.05-0.1 \mathrm{~m}$ inhabitants in 2015 . The initial exposure of largest cities to the most routine and offshorable occupations (MRO) in 1994 is on average lowest in largest cities. The exceptions are Douai-Lens and Lille in the industrial North. The relationship between the employment share of the MRO occupations at the city level in 1994 and the change in the employment share of these jobs over the period 1994-2015 is negative as predicted by Autor and Dorn (2013) (cf. Table E.22 on the robustness of the slope of the fitted line). Conditional on the initial exposure, however, the decline in the MRO occupations is highest in largest cities. Moreover, the average decline in the MRO jobs is not significantly different (cf. Table 5, column 4) between the largest and smallest cities in the sample (which are on average more exposed to those occupations - see Table 4). 
Figure 10 - Exposure to MRO jobs and change in the employment shares of other middle-paid OMP jobs in cities, 1994-2015.

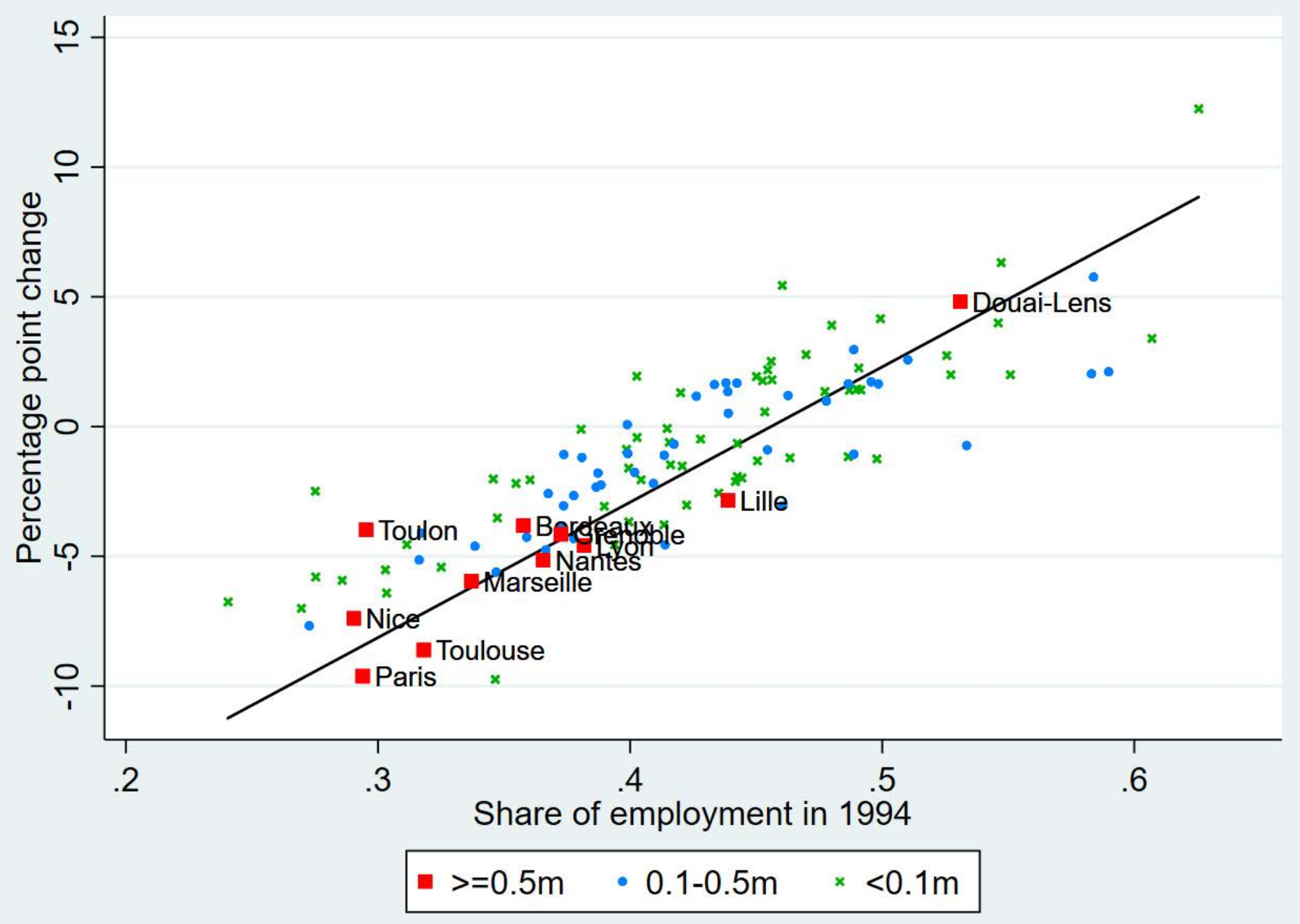

The figure shows the percentage point change in employment shares of OMP jobs (CS 43,46, 47,63, 64 and 65) between 1994-2015 plotted against the share of MRO jobs (CS 48, 54, 62 and 67) in employment in 1994 at the city level. Each red square, blue dot or green check symbolizes, respectively, a large (above $>0.5 \mathrm{~m}$ inhabitants), medium-sized $(0.1-0.5 \mathrm{~m})$ or small $(0.05-0.1 \mathrm{~m})$ city. The line shows a linear, population-weighted (by 1990 population) fit of the relationship between employment changes and the initial MRO exposure. Names of cities with more than $0.5 \mathrm{~m}$ inhabitants are shown. $\mathrm{N}=117 ; 11$ cities $>0.5 \mathrm{~m}, 44$ cities between $0.1-0.5 \mathrm{~m}$ and 62 cities between $0.05-0.1 \mathrm{~m}$ inhabitants in 2015.

The figure depicts a strongly positive population-weighted relationship between the employment share of the MRO occupations at the city level in 1994 and the change in the employment share of OMP jobs over the period 1994-2015 (cf. Table E.22 on the robustness of the slope of the fitted line). In all but one cities with initial exposure to MRO jobs above 0.5 the share of OMP jobs in total employment increased over the period 1994-2015. The decline of the OMP jobs in percentage points is on average stronger in large than in small cities (cf. Table 5, column 5), significant at $1 \%$ level. 
Figure 11 - Labor market polarization and the great divergence across three different city size groups, 1994-2015: 4 employment groups
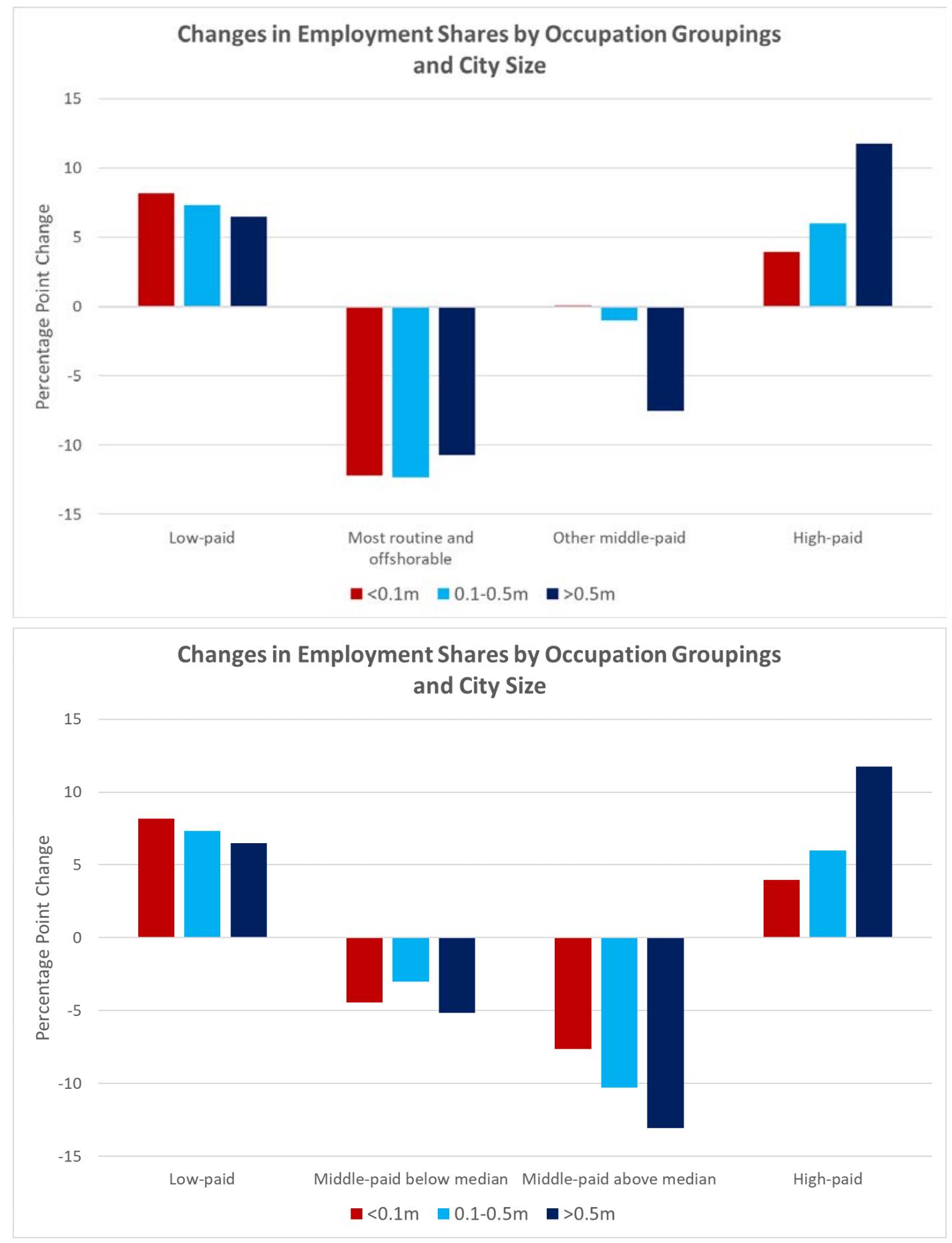

This figure shows percentage point changes in employment shares of high-, low- and different types of middle-paid jobs with hours worked summed by job types and 3 city sizes: large (above $>0.5 \mathrm{~m}$ inhabitants), medium-sized $(0.1-0.5 \mathrm{~m})$ and small $(0.05-0.1 \mathrm{~m})$ in the period 1994-2015. The bars for high- and low-paid jobs are exactly as in Figure 8. The various partitions of middle-paid jobs in each panel order these jobs by median wage. In the upper panel middle-paid jobs are divided into most (MRO) and other middle-paid occupations (OMP). In the lower panel, the division is between the middle-paid jobs with average wages in 1994 above the median (CS 48, 46, 47, 43 and 62 in decreasing wage order) and those below the median (CS 54,65, 63, 64,67).

All of the panels show that, for all these partitions of the middle skill jobs, the destruction of the lower paid jobs was similar across all city sizes. At the same time, the panels show clearly that the destruction of the highest-paid middle-skill jobs rises monotonically with city size. Indeed, OMP occupations actually grow very modestly in the smallest cities. 